\title{
Mobility particle size spectrometers: harmonization of technical standards and data structure to facilitate high quality long-term observations of atmospheric particle number size distributions
}

\author{
A. Wiedensohler ${ }^{1}$, W. Birmili ${ }^{1}$, A. Nowak ${ }^{1}$, A. Sonntag ${ }^{1}$, K. Weinhold ${ }^{1}$, M. Merkel ${ }^{1}$, B. Wehner ${ }^{1}$, T. Tuch ${ }^{1}$, S. Pfeifer ${ }^{1}$, \\ M. Fiebig ${ }^{2}$, A. M. Fjäraa ${ }^{2}$, E. Asmi ${ }^{3}$, K. Sellegri ${ }^{4}$, R. Depuy ${ }^{4}$, H. Venzac ${ }^{4}$, P. Villani ${ }^{4}$, P. Laj ${ }^{5}$, P. Aalto ${ }^{6}$, J. A. Ogren ${ }^{7}$, \\ E. Swietlicki ${ }^{8}$, P. Williams ${ }^{9}$, P. Roldin $^{8}$, P. Quincey ${ }^{10}$, C. Hüglin ${ }^{11}$, R. Fierz-Schmidhauser ${ }^{12}$, M. Gysel ${ }^{12}$, \\ E. Weingartner ${ }^{12}$, F. Riccobono ${ }^{12}$, S. Santos ${ }^{13}$, C. Grüning ${ }^{13}$, K. Faloon ${ }^{14}$, D. Beddows ${ }^{14}$, R. Harrison ${ }^{14}$, \\ C. Monahan ${ }^{15}$, S. G. Jennings ${ }^{15}$, C. D. O'Dowd ${ }^{15}$, A. Marinoni ${ }^{16}$, H.-G. Horn ${ }^{17}$, L. Keck ${ }^{18}$, J. Jiang ${ }^{19}$, J. Scheckman ${ }^{19}$,

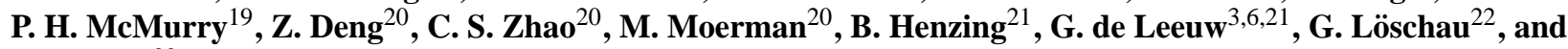 \\ S. Bastian 22 \\ ${ }^{1}$ Leibniz Institute for Tropospheric Research, Permoserstr. 15, 04318 Leipzig, Germany \\ ${ }^{2}$ Norwegian Institute for Air Research, 2027 Kjeller, Norway \\ ${ }^{3}$ Finnish Meteorological Institute, Research and Development, 00101 Helsinki, Finland \\ ${ }^{4}$ Laboratoire de Météorologie Physique, Observatoire de Physique du Globe de Clermont-Ferrand, Université Blaise Pascal, \\ 24 avenue des Landais, 63177 Aubière, France \\ ${ }^{5}$ Laboratoire de Glaciologie et Géophysique de l'Environnement Université Joseph Fourier - Grenoble 1/CNRS, \\ 38400 St Martin d'Hères, France \\ ${ }^{6}$ Department of Physics, University of Helsinki, 00014 Helsinki, Finland \\ ${ }^{7}$ NOAA ESRL GMD, 325 Broadway, Boulder, CO 80305, USA \\ ${ }^{8}$ Division of Nuclear Physics, Lund University, 22100 Lund, Sweden \\ ${ }^{9}$ National Centre for Atmospheric Science, University of Manchester, Manchester, UK \\ ${ }^{10}$ Environmental Measurements Group, National Physical Laboratory, Teddington, Middlesex, UK \\ ${ }^{11}$ EMPA Dübendorf Air Pollution/Environmental Technology, Überlandstraße 129, 8600 Dübendorf, Switzerland \\ ${ }^{12}$ Laboratory of Atmospheric Chemistry, Paul Scherrer Institute, Villigen, Switzerland \\ ${ }^{13}$ European Commission - DG Joint Research Centre, IES/CCU, Ispra, Italy \\ ${ }^{14}$ National Centre for Atmospheric Science, Division of Environmental Health \& Risk Management, \\ University of Birmingham, Edgbaston, Birmingham, B15 2TT, UK \\ ${ }^{15}$ School of Physics \& Centre for Climate and Air Pollution Studies, Environmental Change Institute, \\ National University of Ireland, Galway, Ireland \\ ${ }^{16}$ Institute of Atmospheric Sciences and Climate, Via Gobetti 101, 40129 Bologna, Italy \\ ${ }^{17}$ TSI GmbH, Neuköllner Straße 4, 52068 Aachen, Germany \\ ${ }^{18}$ GRIMM Aerosol Technik GmbH \& Co. KG, Dorfstraße 9, 83404 Ainring, Germany \\ ${ }^{19}$ Department of Mechanical Engineering, University of Minnesota, 111 Church Street SE Minneapolis, MN 55455, USA \\ ${ }^{20}$ Department of Atmospheric Sciences, School of Physics, Peking University, Beijing, 100871, China \\ ${ }^{21}$ TNO Built Environment and Geosciences, 3508 TA Utrecht, The Netherlands \\ ${ }^{22}$ Saxon State Office for Environment, Agriculture and Geology, Pillnitzer Platz, 01326 Dresden, Germany
}

Correspondence to: A. Wiedensohler (alfred.wiedensohler@tropos.de)

Received: 16 November 2010 - Published in Atmos. Meas. Tech. Discuss.: 7 December 2010

Revised: 19 March 2012 - Accepted: 20 March 2012 - Published: 29 March 2012

Published by Copernicus Publications on behalf of the European Geosciences Union. 
Abstract. Mobility particle size spectrometers often referred to as DMPS (Differential Mobility Particle Sizers) or SMPS (Scanning Mobility Particle Sizers) have found a wide range of applications in atmospheric aerosol research. However, comparability of measurements conducted world-wide is hampered by lack of generally accepted technical standards and guidelines with respect to the instrumental setup, measurement mode, data evaluation as well as quality control. Technical standards were developed for a minimum requirement of mobility size spectrometry to perform long-term atmospheric aerosol measurements. Technical recommendations include continuous monitoring of flow rates, temperature, pressure, and relative humidity for the sheath and sample air in the differential mobility analyzer.

We compared commercial and custom-made inversion routines to calculate the particle number size distributions from the measured electrical mobility distribution. All inversion routines are comparable within few per cent uncertainty for a given set of raw data.

Furthermore, this work summarizes the results from several instrument intercomparison workshops conducted within the European infrastructure project EUSAAR (European Supersites for Atmospheric Aerosol Research) and ACTRIS (Aerosols, Clouds, and Trace gases Research InfraStructure Network) to determine present uncertainties especially of custom-built mobility particle size spectrometers. Under controlled laboratory conditions, the particle number size distributions from 20 to $200 \mathrm{~nm}$ determined by mobility particle size spectrometers of different design are within an uncertainty range of around $\pm 10 \%$ after correcting internal particle losses, while below and above this size range the discrepancies increased. For particles larger than $200 \mathrm{~nm}$, the uncertainty range increased to $30 \%$, which could not be explained. The network reference mobility spectrometers with identical design agreed within $\pm 4 \%$ in the peak particle number concentration when all settings were done carefully. The consistency of these reference instruments to the total particle number concentration was demonstrated to be less than $5 \%$.

Additionally, a new data structure for particle number size distributions was introduced to store and disseminate the data at EMEP (European Monitoring and Evaluation Program). This structure contains three levels: raw data, processed data, and final particle size distributions. Importantly, we recommend reporting raw measurements including all relevant instrument parameters as well as a complete documentation on all data transformation and correction steps. These technical and data structure standards aim to enhance the quality of long-term size distribution measurements, their comparability between different networks and sites, and their transparency and traceability back to raw data.

\section{Introduction}

Over the past $10-15 \mathrm{yr}$, mobility size particle spectrometers have been increasingly used for long-term observations of atmospheric particle number size distributions in the submicrometer diameter range. Depending on the instrument, mobility particle size spectrometers cover diameter ranges from 3 to $800 \mathrm{~nm}$ for regular atmospheric observations. Mobility particle size spectrometers are commonly referred to as DMPS (Differential Mobility Particle Sizer) or SMPS (Scanning Mobility Particle Sizer). The particle number size distribution of the atmospheric aerosol is a fundamental, but also an essential parameter required in calculations of the effects of aerosols on climate, human health, and eco-systems. It is also an important parameter with regard to the description of aerosol dynamical processes as well as heterogeneous chemical reactions in the atmosphere.

The first atmospheric long-term measurements (period of several years) with mobility particle size spectrometers were realized in the 1990s at urban observation sites (Tuch et al., 1997; Woo et al., 2001; Charron and Harrison, 2003; Wehner and Wiedensohler, 2003) as well as in the rural and remote areas (Mäkelä et al., 2000; Birmili et al., 2001; Weingartner et al., 1999). Ever since, their application has expanded to a current number of more than 30 ground-based continuous observation points across the globe, whose measurement data are used for a wide range of purposes. Within the European research infrastructure projects EUSAAR (European Supersites for Atmospheric Aerosol Research) and ACTRIS (Aerosols, Clouds, and Trace gases Research InfraStructure Network), EMEP (European Monitoring and Evaluation Program), and the integrated research project EUCAARI (European Integrated project On Aerosol Cloud Climate Air Quality Interactions), mobility particle size spectrometers were implemented at more than 20 ground-based atmospheric observational "supersites" in Europe. As more and more measurement sites and institutions become involved, technical standardization of custom-built and commercial instruments, harmonization of the data evaluation, quality control, and data dissemination are needed to obtain a minimum comparability and accuracy of the data sets.

Most modern mobility particle size spectrometers operate a differential mobility analyzer (DMA; for a general theoretical background see, e.g. Knutson and Whitby, 1975; Liu and Pui, 1974; Flagan, 1999; Stolzenburg and McMurry, 2008) upstream of a condensation particle counter (CPC; Agarwal and Sem, 1980; Stolzenburg and McMurry, 1991; Wiedensohler et al., 1997; Hermann et al., 2007), which records particle number concentrations as a function of the electrical particle mobility by varying the DMA voltage. Mobility particle size spectrometers were developed over the last $30 \mathrm{yr}$ (e.g. ten Brink et al., 1983; Fissan et al., 1983; Kousaka et al., 1985; Winklmayr et al., 1991; Wang and Flagan, 1990; Chen et al., 1998). 
Commercial mobility particle size spectrometers have been available since the 1980 s and with automatic flow control only during the past $15 \mathrm{yr}$. Two examples of commercial devices are instruments from TSI Inc. (Shoreview, MN, USA) and Grimm GmbH (Ainring, Germany). Commercial mobility particle size spectrometers are generally not optimized for long-term atmospheric measurements. Several groups in the atmospheric research community have thus developed custom-designed mobility particle size spectrometers in the past (e.g. Jokinen and Mäkelä, 1997; Birmili et al., 1999).

Although mobility particle size spectrometry was established in the 1970s, published reports on the actual quality of the data as well as instrumental comparisons are scarce. The World Meteorological Organization issued recommendations for the design and the operation of continuous atmospheric aerosol measurements in general (WMO, 2003; World Meteorological Organization-Global Atmosphere Watch), but recommendations for mobility particle size spectrometers were omitted. Few intercomparisons of mobility particle size spectrometer measurements have been published. Khlystov et al. (2001) identified systematic differences between three different mobility particle size spectrometers used for atmospheric measurements. During a workshop investigating diesel exhaust, eleven instruments were compared for the first time (Dahmann et al., 2001). They concluded that different instruments (of the same and also different designs) may yield similar particle number size distributions, but emphasized that the constant supervision of the equipment in the laboratory by qualified personnel was necessary. Imhof et al. (2006) compared four different mobility spectrometers in a road tunnel experiment. They found discrepancies in the concentrations of particle number size distributions of $30 \%$ in the size range smaller than $50 \mathrm{~nm}$, approximately $25 \%$ for the size range from 60 to $200 \mathrm{~nm}$, and $10 \%$ for particle greater than $200 \mathrm{~nm}$ in diameter. The reasons for these discrepancies were not clear. Helsper et al. (2008) published the results from a VDI-initiated study ("Verein Deutscher Ingenieure", The Association of German Engineers), which compared four commercial mobility particle size spectrometers (TSI long-SMPS, TSI nano-SMPS and two Grimm-SMPS) and a custom-made IFT-TDMPS (Twin-DMPS; based on Birmili et al., 1999). Integrated particle number concentrations compared well $( \pm 12 \%)$ over the limited size range of $40-350 \mathrm{~nm}$ for all instruments with the exception of the TSI nano-SMPS, which had a limited size range up to $200 \mathrm{~nm}$. The concentrations of the particle number size distributions differed by a maximum of $25 \%$ within the size range of 20 $200 \mathrm{~nm}$ although larger discrepancies occurred outside this range. The reasons for the instrumental deviations could not be rigorously assessed, because of unknown differences in the multiple charge inversion algorithms used by the different manufacturers.

An intercomparison of custom-built mobility spectrometers has not been published to date, particularly in comparison to commercial instruments. Furthermore, no publications exist in which inversion routines of mobility particle size spectrometers were systematically compared. Inversion routines are the vital basis for converting measured electrical particle mobility distributions into final particle number size distributions taking into account the bipolar charge distribution as well as the DMA (Differential Mobility Analyzer) transfer function. Possible sources of uncertainty in particle number size distribution measurements include the DMA transfer function, particle losses, the sizeand material-dependent CPC counting efficiency, or differences in the bipolar charge distribution. Instabilities in the aerosol or sheath flow rates as well as an unmeasured relative humidity in an instrument are likely to cause uncertainties in the particle number concentration and sizing. Inconsistent practices among the scientific groups regarding the measurement and automatic monitoring of such instrumental parameters made it difficult to evaluate the quality of reported particle number size distributions. Most scientists usually only report final particle number size distributions, making it difficult to trace instrumental differences back to the level of measured raw number concentrations.

The described inconsistencies and uncertainties in technical performance and undefined data quality lead to a need to harmonize technical standards of mobility particle size spectrometers and the data structure to ensure high data accuracy, comparability, transparency, and traceability of the measured particle number size distribution.

In this paper, we recommend minimum technical standards for the design and the operation of mobility particle size spectrometers including the submission of data and metadata to data archives. An additional goal is that our recommendations should be adapted for commercial mobility particle size spectrometers in the future. The experiments of these investigations were performed within the frame of the European research infrastructure projects EUSAAR and ACTRIS, the network of Excellence ACCENT (Atmospheric Composition Change: a European Network), the WMOGAW programme (Global Atmosphere Watch), and EMEP (European Monitoring and Evaluation Program).

\section{The principles of mobility particle size spectrometers}

This section briefly outlines the physical principles of modern mobility particle size spectrometers. For more details, the reader is referred to reports on the development of mobility particle size spectrometers (e.g. ten Brink et al., 1983; Fissan et al., 1983; Kousaka et al., 1985; Wang and Flagan, 1990; Winklmayr et al., 1991; Chen et al., 1998; Jokinen and Mäkelä, 1997; Birmili et al., 1999; Hinds, 1999), or the documentation provided by commercial manufacturers. Most mobility particle size spectrometers consist of a sequential setup of a bipolar diffusion charger (or traditionally named neutralizer), a DMA, and a CPC. By setting different voltages 
in the DMA, particles of different electrical mobility are selected and their particle number concentration can be measured. Ramping or stepping the voltage yields an electrical particle mobility distribution, which can later be inverted into a particle number size distribution.

Before the aerosol particles enter the DMA, they are brought to a bipolar charge equilibrium using a bipolar diffusion charger. This bipolar charge equilibrium can be theoretically described by the work of Fuchs (1963) and Gunn (1956). Positive and negative ions are produced continuously in this bipolar diffusion charger, for instance by a radioactive source. The radioactive sources used in field observation include ${ }^{85} \mathrm{Kr},{ }^{14} \mathrm{C}$, and ${ }^{63} \mathrm{Ni}$ (both beta-radiators), and ${ }^{241} \mathrm{Am}$ and ${ }^{210} \mathrm{Po}$ (both alpha-radiators). To achieve a bipolar charge equilibrium (see Appendix A5), the particle number concentration should be significantly lower than the equilibrium ion pair concentration, which is believed to be approximately $10^{7} \mathrm{~cm}^{-3}$. Mobility particle size spectrometers can be thus only used for total particle number concentrations up to $10^{6} \mathrm{~cm}^{-3}$. A complication is that alpha-particles emitted from radioactive sources such as ${ }^{241} \mathrm{Am}$ and ${ }^{210} \mathrm{Po}$ lose their energy within $5 \mathrm{~cm}$ traveling distance in air and produce beside air ions also ozone leading to the production of unintended nucleation particles.

A DMA is usually built as a cylindrical capacitor. The charged aerosol is thus injected through an annular slit closed to the outer electrode into the DMA and then merged with the particle-free sheath air flow. All flows should be strictly laminar. In the DMA, charged particles are separated according to their electrical particle mobility. The electrical particle mobility depends primarily on particle charge (proportional) and particle diameter (inversely), but also on the gas viscosity (see Appendix A5), particle shape, Cunningham correction factor, and hence also indirectly on temperature and pressure of the gas flowing inside the DMA (e.g. Hinds, 1999). The smaller the particle diameter and the higher the number of charges, the larger is thus the electrical particle mobility. By knowing the dimensions of the DMA (length and diameters of the inner and outer electrode), one can calculate the voltage between the electrodes needed to transport charged particles with a certain electrical particle mobility from the entrance to the annular slit in the center rod of the capacitor. The sample flow carrying particles with the same small range of electrical particle mobility is drawn through this small slit. The particle number concentration in this sample flow is measured in a CPC. The electrical particle mobility distribution is determined by scanning the voltage through the entire electrical particle mobility range to be investigated.

Usually, the set-up of a mobility particle size spectrometer requires upstream of the DMA the deployment of a pre-impactor. The role of this pre-impactor is to remove all particles larger than the upper size limit of the mobility particle size spectrometer. This ensures that no multiple charged particles with sizes larger than the measurement range can interfere with the measured electrical particle mobility distribution, which is a pre-requisite for a correct multiple charge inversion scheme. The impactor can be omitted for most atmospheric applications, if the size range of the mobility particle size spectrometer extends up to $800 \mathrm{~nm}$ or more. The reason is that the atmospheric particle number size distribution declines very steeply towards larger particle sizes, making the contributions of multiple charged particles much less. Sensitivity tests have shown that multiple charges on particles larger than $800 \mathrm{~nm}$ diameter are only important in the case of exceptional amounts of these large particles, such as during dust events (Birmili et al., 2008; Schladitz et al., 2009) or for the marine aerosol.

The particle number size distribution is derived from the measured electrical particle mobility distribution with an inversion routine (Hoppel, 1978; Knutson, 1976; Hagen and Alofs, 1983; Stratmann and Wiedensohler, 1996; Stolzenburg and McMurry, 2008). The knowledge of the bipolar charge distribution is used here (Fuchs, 1963; Wiedensohler, 1988; Baron and Willeke, 2005; see also Appendix A5).

A DMA transfer function (Birmili et al., 1997; Knutson and Whitby, 1975; Stolzenburg, 1988; Russel et al., 1995; Collins et al., 2002; Hagwood et al., 1999; Zhang and Flagan, 1996) might be also employed to include losses in the DMA directly in the data inversion. Birmili's method is based on a triangular ideal transfer function, which may lead to small uncertainties. Later, the particle number size distribution can be corrected by the CPC counting efficiency function (e.g. Agarwal and Sem, 1980; Stolzenburg and McMurry, 1991; Wiedensohler et al., 1997; Hermann et al., 2007) estimations of internal losses by diffusion.

The quality of the measurements of mobility particle size spectrometers depends essentially on the stability of the aerosol and sheath air flow rates as well as the performance of the CPC. An error in the sheath air flow rate of $1 \%$ corresponds to a shift of $1 \%$ in the selected electrical particle mobility. For the typical ratio of sheath air flow rate to sample air flow rate, 10:1, a leak in the loop of the sheath air flow of $1 \%$ would cause a $10 \%$ error in the aerosol flow rate. A change in the aerosol flow translates directly into the measured particle number concentrations. Furthermore, particle-contaminated sheath air or leaks between DMA and CPC cause rather large errors. It is also essential to calculate the DMA voltages for the actual temperature and pressure conditions encountered at the field station (or particle mobility from a given voltage). It is appropriate to calculate the voltages on the basis of mean indoor temperature and pressure at the station, and additionally to monitor pressure and temperature in the instrument as confirmation. A pressure variation of $\pm 30 \mathrm{hPa}$ leads to an uncertainty of approximately $1 \%$ in sizing and is thus tolerable, while temperature fluctuations within $\pm 10^{\circ} \mathrm{C}$ are not critical in sizing. It is thus vitally important to use the correct mean pressure when operating instruments at higher altitudes.

Another important issue for atmospheric particle number size distributions is the relative humidity $(\mathrm{RH})$ in the 


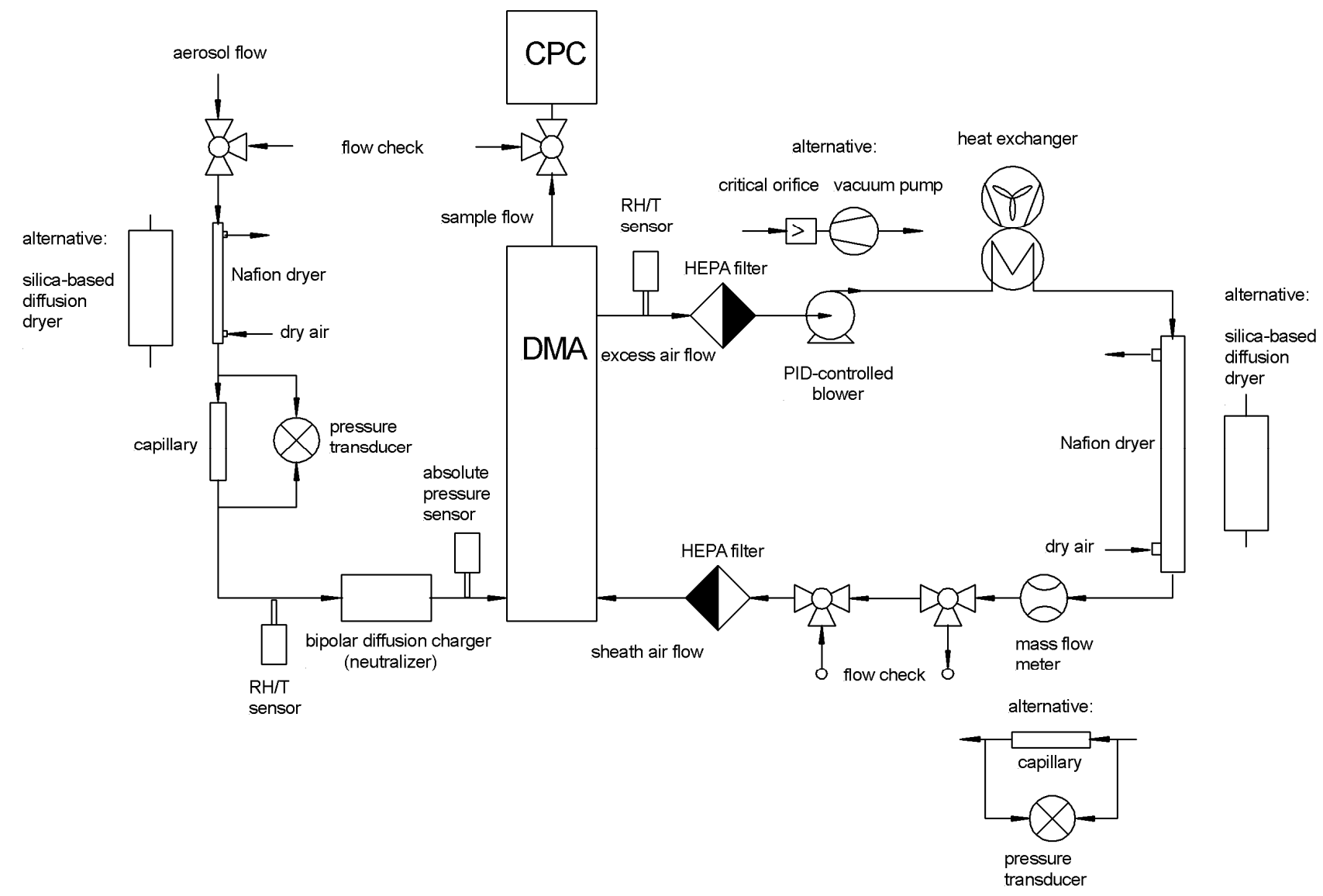

Fig. 1. Schematic sketch of the recommended closed-loop mobility particle size spectrometer. The set-up includes dryers for aerosol flow and sheath air, heat exchanger, particle filters, as well as sensors for aerosol and sheath air flow rate, relative humidity and temperature of aerosol flow and sheath air, and absolute pressure.

instrument. Atmospheric aerosol particles containing watersoluble material may take up significant amounts of water well below saturation. This effect is called hygroscopic growth. Ambient air may increase considerable their RH when cooled down after entering an air-conditioned laboratory. Hygroscopic growth factors in the range from 1.3-1.6 of atmospheric particles larger than $100 \mathrm{~nm}$ in diameter at a RH of $90 \%$ is common (Swietlicki et al., 2008), however, depending on the mass fraction and state of mixing of watersoluble particle material. The solution to achieve comparability between measurements is to limit the relative humidity by drying the sample aerosol. Preferably, the RH should be kept below $40 \%$, which minimizes diameter changes due to hygroscopic growth to typically less than $5 \%$ (Swietlicki et al., 2008).

\section{Harmonization of the technical standard}

Within the EUSAAR and ACTRIS projects, we developed technical standards for mobility particle size spectrometers. Parts of these standards have resulted from the desire to harmonize aspects of hardware, and enhance the accuracy and definition of the measurement. Others were conceived to enhance the data formatting and evaluation procedure of the measurements. The recommended standards have been clearly motivated by the needs of long-term field experiments, nurtured by a multi-annual practice of field observations and laboratory intercomparisons of mobility particle size spectrometers. The general spirit of these recommendations is to enhance the accuracy and world-wide comparability of such measurements. We encourage operators of atmospheric measurements of particle number size distributions to adhere to these standards as far as possible.

\subsection{Technical features of the mobility particle size spectrometers}

The schematic of our recommended mobility particle size spectrometer is shown in Fig. 1. Here, the sheath air flow is circulated in a closed loop, a principle implemented in most commercial and custom-made mobility particle size spectrometers. The recommended set-up includes dryers to reduce $\mathrm{RH}$ in the aerosol sample and sheath air flows. The 
dryer in the sheath air flow helps to avoid to startup measurements with moist air somewhere in the DMA and the relative humidity become more stable. Furthermore, it would take longer to get all the flows and HEPA (High Efficiency Particle) filters dry if the sheath air dryer is eliminated. The sheath air loop contains a heat exchanger and HEPA filters. Sensors continuously record the aerosol and sheath air flow rates, relative humidity and temperature in both flows, and absolute pressure in the aerosol flow entering the DMA.

For scanning mobility particle size spectrometers, we recommend to use a minimum scanning time (up or down scan) of 2 min to avoid smearing effects in the particle counters with a relatively slow responds time. These smearing effects can cause e.g. significant false measurements at the slope towards larger particles in the accumulation mode range.

\subsubsection{Relative humidity $(\mathrm{RH})$ control and measurement}

Due to the hygroscopic growth of atmospheric aerosol particles at RH well below supersaturation, it is essential to control or limit RH in mobility particle size spectrometers. The philosophy is to obtain comparable data sets and therefore to measure the "dry" particle number size distribution. When working in warm and moist atmospheric environment, the dew point temperature can reach the standard temperature of a measurement laboratory $\left(20-25^{\circ} \mathrm{C}\right)$. The consequence is that the aerosol sample flow has to be dried, either directly in the main sampling line or at the instrument. A dry aerosol sample is needed to ensure the correct bipolar charge equilibrium and thus sizing downstream of the bipolar diffusion charger in the DMA. A dry sheath air is needed to ensure particle sizing inside the DMA with a minimum fluctuation in $\mathrm{RH}$.

Our recommendation is to limit $\mathrm{RH}$ inside an instrument to below $40 \%$. In this regime, changes in particle diameter as a result of $\mathrm{RH}$ are expected to be below $5 \%$.

To limit RH in the aerosol sample flow, we concretely recommend to use a membrane dryer (made from materials such as Nafion $^{\mathrm{TM}}$ ), or a silica-based aerosol diffusion dryer. Operation of a membrane dryer will require a continuous supply of dry air in the laboratory, while a silica-based dryer will require regular regeneration. Utmost care should be taken to select or design dryers that feature minimum particle losses, such as due to Brownian diffusion. Ideally, particle losses across the dryer are characterized and accounted for in the data processing as an equivalent pipe length (see below).

In complete analogy, the sheath air flow rate should be dried below $40 \% \mathrm{RH}$ as well. Both membrane and diffusion dryers can be used. RH in the sheath air flow should be monitored continuously by a calibrated humidity sensor as well. The sheath air RH sensor should be installed as close as possible to the DMA at the excess air outlet. The objective is to measure $\mathrm{RH}$ at a temperature and pressure that best represent the conditions inside the DMA. As a guideline, the temperature of the sheath air RH sensor should not differ more than $1 \mathrm{~K}$ from the temperature in the DMA.

$\mathrm{RH}$ in both the aerosol and sheath air flows should be monitored continuously by calibrated humidity sensors with a maximum uncertainty of maximum $5 \% \mathrm{RH}$ across the range of 10-90\%. These data should be recorded and stored with at least the same time resolution as the electrical particle mobility distributions. When dual mobility particle size spectrometers (systems with two parallel DMAs) such as a TDMPS (Twin Differential Mobility Particle Sizer) are used to encompass a wider particle size range (e.g. below $10 \mathrm{~nm}$ ), the RH parameters should be separately reported for each DMA.

\subsubsection{Sheath air flow circuit specifications}

In the case of a closed-loop sheath air flow, such as illustrated in Fig. 1, a heat exchanger is needed to remove the excess heat generated by the pump or blower. An ideal instrument employs two HEPA filters to provide particle-free sheath air at the exit from and entrance to the DMA. The pressure drop across the HEPA filters should be minimal to ensure a correct measurement in the closed loop of the sheath air flow. For a critical orifice/pump set-up, the absolute pressure downstream of the critical orifice should be monitored to ensure critical flow conditions (pressure downstream less than half of the upstream pressure).

\subsubsection{Aerosol and sheath air flow measurement}

One of the important, but sometimes apparently underestimated issues in particle electrical mobility measurements is the correct determination of the instrumental air flows. Errors in the experimental aerosol and sheath flow rates will propagate immediately into the derived particle number concentrations and/or particle sizes. Our general advice is to combine continuous and automated flow measurements inside the instrument with the manual precision measurements that are typically part of regular maintenance. To ensure continuous observations of the aerosol and sheath air flow, our recommended set-up includes the use of calibrated flow meters in the respective positions (Fig. 1).

For the aerosol flow, we recommend to use a calibrated differential pressure transducer measuring the pressure drop across a laminar flow element (capillary). While such a capillary can be manufactured from widely available plumbing elements, care should be taken to warrant an undisturbed laminar flow across the device. It is particularly not recommended to use mass flow meters for the aerosol flow, because of particle losses. The measured flow values should be recorded and stored with at least the same time resolution as the measured electrical particle mobility distributions. As a guideline for quality control, the continuously recorded aerosol flow should not deviate more than $5 \%$ from the setpoint. Besides the continuous measurement, the aerosol flow needs to be checked manually using a precision volumetric 
flow meter (e.g. an electrical bubble flow meter). This manual measurement should take place as often as possible, but at least at each service occasion. The quality of the continuous flow measurement will be improved if the differential pressure transducer is recalibrated regularly.

For the sheath air flow measurement, two options are possible: either a differential pressure flow meter as described above, or a mass flow meter - because particle losses do not matter inside the sheath air flow. To capture the flow rate under conditions as close to the conditions (pressure, temperature) inside the DMA, the flow meter should be installed near the sheath air inlet (but upstream of the HEPA filter). For differential pressure flow meters, the sensor voltage is typically calibrated against a reference volumetric flow. Any mass flow meter should also be calibrated for volumetric flow using a reference volumetric flow meter, thereby accounting for air pressure and temperature in the laboratory. As a guideline, the sheath air flow should be kept as constant as possible, with a maximum deviation of its floating average of $2 \%$ around the set-point value. The required temporal stability can be accomplished either by a critical orifice/pump set-up or by an air blower that is controlled by software or hardware.

\subsubsection{Temperature and pressure}

To ensure the highest quality and traceability of mobility particle size spectrometer measurements, temperature and absolute air pressure should be monitored in the instrument. The objective is to determine the conditions given at any time inside the DMA, because these are needed to ascertain the correct sizing of the particles and to adjust the final particle number size distributions to standard conditions (273.15 K, 1013.25 hPa) below (see Appendix A4.3). The preferred option is to monitor temperature and absolute air pressure near the aerosol inlet of the DMA (Fig. 1), however, without disturbing the laminar flow profile. Since RH sensors are usually capable of recording temperature as well, it is useful to store the temperatures values from those positions as well. As mentioned before, all parameters should be stored with at least the time resolution of the measured electrical mobility distribution. In the case of dual mobility particle size spectrometer, it is obligatory to report the parameters recorded separately in conjunction with each DMA.

\subsection{Electrical and mechanical units, and constants}

In the past, the comparability of measurements of mobility particle size spectrometer has been hampered by the diverging use of electrical and mechanical units and/or constants. Our recommendations are designed to enhance direct mutual comparability of different data sets, and to avoid confusion for less experienced users.

A first recommendation is to indicate electrical particle mobility distributions as a function of nominal particle size, i.e. the equivalent mobility particle diameter for singly charged particles. This allows comparing directly raw electrical particle mobility distributions of different instruments, regardless of their specific dimensions and air flows. The indication of raw electrical particle mobility distributions as a function of nominal particle size allows any operator as well as external user to easily recalculate the multiple charge inversion and any kind of subsequent data correction. The possibility to recalculate the data is a vital element towards a higher traceability and transparency of the measured data.

Calculation of the mobility particle diameter requires the dynamic viscosity and the mean free path of air as function of temperature and pressure. We strongly recommend using the constants and formulas of ISO 15900, as given below in Appendix A5.

The knowledge of the bipolar charge distribution is essential to perform the multiple charge correction to calculate the particle number size distribution from the measured electrical particle mobility distribution. Our advice is to use the bipolar charge distribution given in ISO 15900. This bipolar charge distribution is based on the approximation formulas and the Gunn (1956) equation published by Wiedensohler (1988) with corrections to two approximation coefficients published in Baron and Willeke (2005). The approximation coefficients are listed in Appendix A5.

\subsection{Correction of particle losses}

Particle losses may practically occur in any part of a mobility particle size spectrometer. An important mechanism is particle diffusion to walls e.g. inside of pipes, the DMA, aerosol dryer and bipolar charger, especially for particles smaller than $100 \mathrm{~nm}$ in size. If particle losses in a particularly device are known as a function of particle size, they can be corrected during the data post-processing. A useful parameter to describe particle losses in any component of the mobility particle size spectrometer is the method of "equivalent pipe length". Particle losses by diffusion of different components of the mobility particle size spectrometers are described by a straight pipe, which has the same particle penetration (equivalent pipe length). The losses can thus be easily computed for any particle size and flow rate from such an equivalent pipe length. Equivalent pipe lengths of different devices and plumbing elements aligned in sequence can be simply added if they are traversed by the same rate of aerosol flow. To ensure traceability of the data, any such corrections need to be documented when submitting data to a data base.

\subsubsection{Plumbing}

Particle losses by diffusion in a straight pipe can be described by analytical formulas derived for the laminar flow regime (Hinds, 1999). For a developed laminar flow, these losses depend only on the pipe length, the flow rate through the pipe, and the particle size. When designing a mobility particle size spectrometer, it is advisable to use connecting pipes as short 
Table 1. Equivalent pipe lengths of different components of mobility particle size spectrometers to calculate diffusional particle losses.

\begin{tabular}{lll}
\hline Device & \multicolumn{2}{l}{ Equivalent pipe length } \\
\hline Hauke-type medium-DMA (28 cm effective length) & $4.6 \mathrm{~m}$ & Karlsson and Martinsson (2003) \\
Hauke-type short-DMA (11 cm effective length) & $4.6 \mathrm{~m}$ & IFT internal calibration \\
TSI long-DMA (444 mm effective length) & $7.1 \mathrm{~m}$ & Karlsson and Martinsson(2003) \\
TSI nano-DMA (49.9 mm effective length) & $3.64 \mathrm{~m}$ & Jiang et al. (2011) \\
Permapure Nafion dryer SS24" & $2.5 \mathrm{~m}$ & Dick et al. (1995) \\
Permapure Nafion dryer SS12 & $1.25 \mathrm{~m}$ & Dick et al. (1995) \\
Diffusion dryer (e.g. TOPAS) & $5 \mathrm{~m}$ & estimated from inlet diffusion dryer in Tuch et al. (2009) \\
90 bend (less than 5 cm radius) & $0.15 \mathrm{~m}$ & estimated from Wang et al. (2002) \\
Bipolar diffusion charger (here, IFT custom-made) & $1 \mathrm{~m}$ & Covert et al. (1997) \\
\hline
\end{tabular}

as possible, and as straight as possible. Enhanced diffusional particle losses may occur in sampling pipes containing bends or elbows. These enhanced particle losses increase with a decreasing radius of the bend or elbow. We estimated the equivalent pipe length of a $90^{\circ}$ bend based on the investigation of Wang et al. (2002). Using curves with smooth radii instead of elbow joints will also reduce the opportunity for particle losses. It is very essential that the plumbing consists of electrical conducting material, preferably stainless steel. Experience has shown that non-conductive tubing (e.g. plastics) may remove a considerable fraction of any charged particles by electrostatic forces.

\subsubsection{Bipolar diffusion charger}

Particle losses also occur inside bipolar diffusion chargers. The loss correction can be directly applied based on the experimentally determined penetration efficiency. Alternatively, any experimental penetration efficiency under a specific flow can be converted to an equivalent pipe length using the diffusional deposition formula for laminar flow (Hinds, 1999). Covert et al. (1997) determined particle losses for sub-10 nm particles across ${ }^{85} \mathrm{Kr}$ bipolar diffusion chargers (IFT custom-made; Table 1). Wang et al. (2007) reported experimental and calculated penetration efficiencies for ten different types of bipolar diffusion chargers.

\subsubsection{Differential mobility analyzer}

Different DMA types exhibit different particle losses due to Brownian diffusion. The probability of a particle penetrating through a DMA depends on the losses in the DMA inlet and outlet region as well as on the transfer function in the DMA classification region. Short column lengths and high aerosol and sheath air flows are general design features that minimize particle losses. Particle losses can be either simulated by diffusional deposition models, or estimated experimentally (e.g. Stolzenburg, 1988; Fissan et al., 1996; Birmili et al., 1997). As with the bipolar diffusion charger, the diffusional losses across different DMAs have been simulated by an equivalent pipe length as given in Table 1 (e.g. Reineking and Porstendorfer, 1986; Karlsson and Martinsson, 2003; Jiang et al., 2011).

\subsubsection{Condensation particle counter}

Each CPC may have a rather individual particle counting efficiency, which can be determined experimentally. The sizedependent counting efficiency of an individual CPC may depend on many specific factors, such as CPC geometry, or the actual supersaturation profile inside the condenser. If experimental data on the counting efficiency of a particular CPC are not available, the manufacturer's calibration curve can be applied with caution. Our recommendation is, however, to calibrate CPCs individually against a reference instrument. Experience suggests that the performance of CPC degrades typically after one year of continuous ambient measurements due to laser power deterioration or contamination of the optics. When calibrating a CPC (Liu and Pui, 1974), particle losses inside the CPCs are implicitly included in the measured counting efficiency. Particle losses inside CPCs are primarily caused by diffusion and can be estimated using diffusional deposition models (Stolzenburg and McMurry, 1991).

\section{Intercomparison studies}

\subsection{Inversion routines}

Our intercomparison of inversion routines includes 12 different variants operated by the project participants (research groups and commercial companies). As a test bed, one day of electrical particle mobility distribution measurements of ambient aerosol (particle number concentrations versus mobility particle diameter classes) were supplied to each group to run their individual inversion routine.

All inversion routines used the multiple charge correction for negatively charged particles. The pragmatic reason was that most participating groups apply positive voltages to their mobility particle size spectrometers. This also meant that 
some groups ran their inversion program in a non-standard fashion for this investigation. Short descriptions of all inversion routines are given in Table A2 in Appendix A.

To make the calculations comparable, an ideal DMA transfer function for all inversion programs was used (Knutson and Whitby, 1975). Apart from "Grimm old" (using Boltzmann charging probabilities for large particles), all inversion routines used the ISO 15900 recommendations (Determination of particle size distribution - Differential electrical mobility analysis for aerosol particles) for the bipolar charge equilibrium. As shown in the upper plots of Fig. 2a and b, the particle number size distributions determined by the different inversion routines visually agreed with some small differences. The shaded area represents the $\pm 5 \%$ range around the results of the IFT inversion routine.

To see small differences as function of particle size, we plotted the ratio of the results of any individual inversion routine against the IFT one (lower plots in Fig. 2a and b). Apart from "Old Grimm", which is not used anymore in newer software routines, all inversion routines agreed within $5 \%$ over the size range $5-300 \mathrm{~nm}$. Only towards the end of the size range, some discrepancies occur. These differences are probably caused by interpolating of the electrical mobility distribution to obtain the individual data format for the individual inversion routine. The results give us the confidence that significant differences in particle number size distribution by comparing mobility particle size spectrometers are not due to the applied inversion routines.

\subsection{CPC counting efficiency curves}

Correct measurement of the particle number size distribution for the smallest particle sizes depends critically on the sizedependent particle detection efficiency of the CPC. In order to ensure long-term quality-assured data, the CPC should be technically checked and/or calibrated preferably against a reference standard every year. Ideally, the CPC is compared to a reference instrument at the calibration facility of the observational network or at the manufacturer.

An accurate determination of the detection efficiency curve of a CPC depends strongly on the traceability of the reference instrument such as an aerosol electrometer, which measures the electric current of charged particles in an air flow. Attempts were recently taken to provide defined charged aerosol particles for CPC calibrations (Yli-Ojanperä et al., 2010; Fletcher et al., 2009). From electric current measured by the electrometer, the particle number concentration can be directly calculated by knowing the exact aerosol flow rate and assuming only singly charged particles. Since the electrical current can be low as $10^{-15} \mathrm{~A}$, the signal has to be highly amplified by a factor of $10^{12}$. The uncertainty of the measurements depends thus on the uncertainty of the resistance in the amplifier circuit.

In the following, we describe the determination of the counting efficiency of CPCs as presently done at the
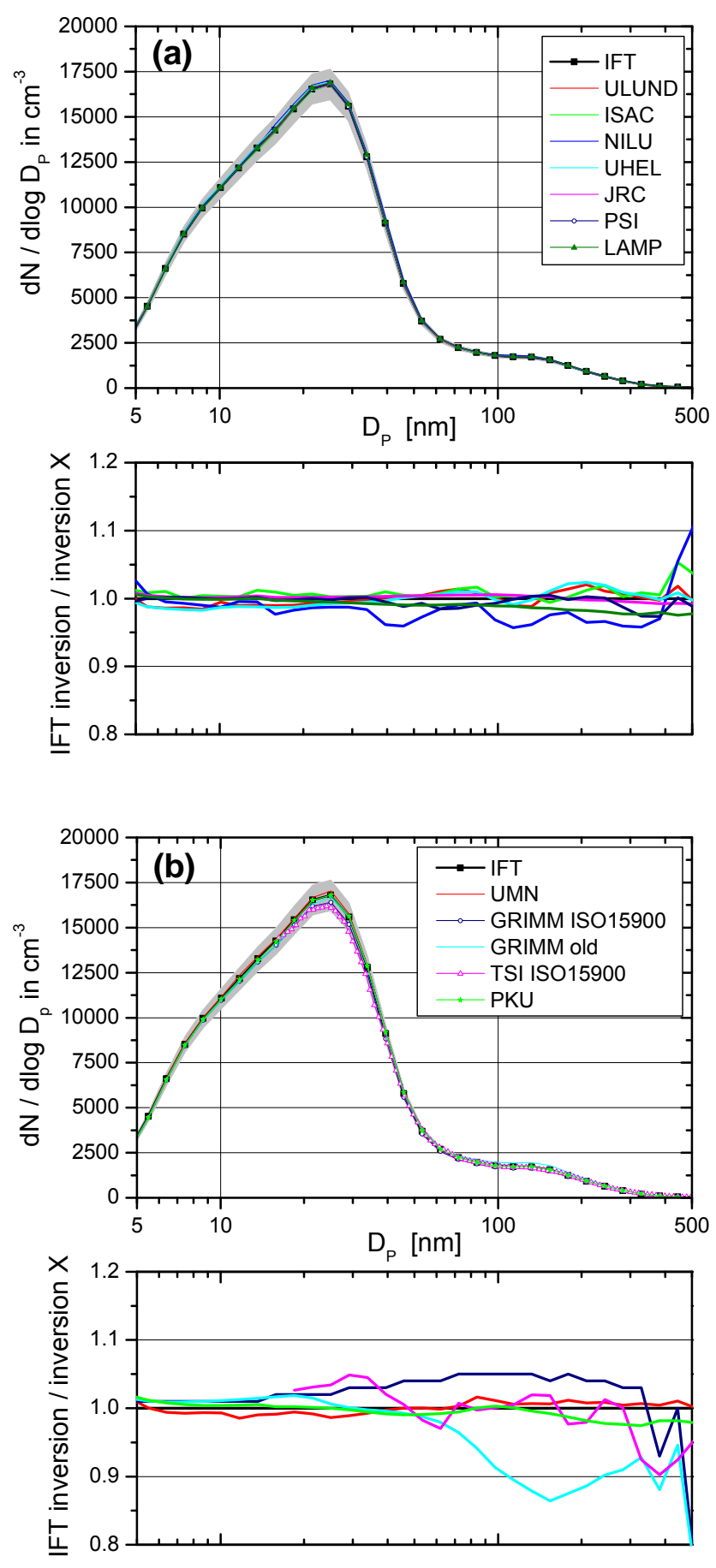

Fig. 2. Comparison of the inversion routine of different customprogrammed and commercial mobility particle size spectrometers using an ideal transfer function and no correction for particle losses due to diffusion. In the upper graphs of (a) and (b), the shaded areas mark the $\pm 5 \%$ range around the output of the IFT inversion. The lower graphs show the ratio of the IFT inversion to the different inversion outputs. 
WMO-GAW-WCCAP in Leipzig (World Calibration Centre for Aerosol Physic) within the EUSAAR, ACTRIS, and GAW networks (Wiedensohler et al., 1997). The results of the CPC calibration in the frame of the third EUSAAR DMPS/SMPS intercomparison workshop (Sect. 4.3) held in Leipzig 2009 are shown here as an example. Briefly, we nucleate a silver aerosol in a tube furnace (Scheibel and Porstendörfer, 1983) and select monodisperse particles in the range from 3-40 nm using a DMA. For the size range up to $40 \mathrm{~nm}$, we achieve after the DMA mainly singly charged particles. Due to the relatively small degree of polydispersity of the aerosol from the furnace generator (geometric standard deviation of 1.3-1.4), the concentration of double charged particles up to $40 \mathrm{~nm}$ is negligible. After dilution, the response of each CPC was then compared against a reference electrometer as a function of particle diameter. All particle counters and the aerosol electrometer were connected to a common manifold that was designed to minimize particle losses.

In the first calibration step, we used ten condensation particle counters (models TSI 3010 and 3772) and compared the particle number concentration for $40 \mathrm{~nm}$ particles. Taking into account the actual flow rate of each particle counter, the unit-to-unit variability was maximum $\pm 3 \%$ at $40 \mathrm{~nm}$ around the mean value. Since the exact amplification of the aerosol electrometer used in the workshop 2009 was not known, we defined the average counting efficiency of these CPCs as $100 \%$. This is a necessary assumption to define an absolute measure. The average particle number concentration was then compared to the value given by aerosol electrometer. We obtained the gain error of our electrometer to $7 \%$, which was then used to calculate the CPC counting efficiencies for the size range smaller than $40 \mathrm{~nm}$. Presently, the accuracy was not determined. This could only be done by an electric current calibration of the aerosol electrometer with a very high precision. The selected particle sizes were not correct for particle dispersion in the DMA.

The resulting detection efficiency curves are shown in Fig. 3. Four CPCs were set to a higher temperature difference of $25^{\circ} \mathrm{C}$ between saturator and condenser, while the other CPCs were operated at the nominal, factory-set temperature difference of $17^{\circ} \mathrm{C}$ or $25^{\circ} \mathrm{C}$ for the TSI-3034-CPC (TNO instrument). The counting efficiency curves can be used later to correct the particle number size distribution measurements. It can be seen that the $50 \%$ detection efficiency diameter of the different CPCs depends significantly on the particular design, but also on operational parameters, particularly the condenser/saturator temperature difference. Furthermore, CPCs operating with the nominal, factory-set temperature difference may also differ by a few nanometers in their actual $50 \%$ detection efficiency diameter.

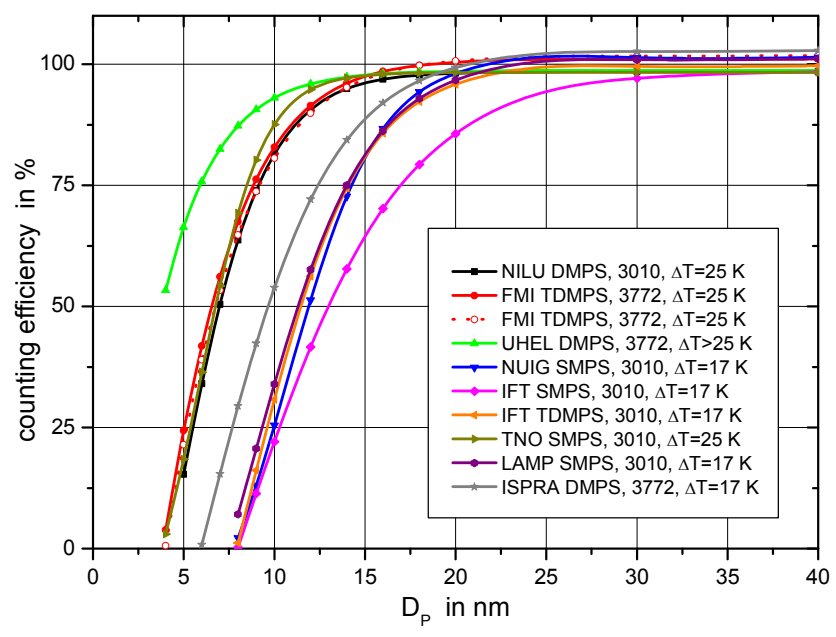

Fig. 3. Examples of detection efficiency curves measured during the third CPC calibration workshop. The $50 \%$ detection efficiency diameter shifts to smaller sizes by employing a higher $\Delta T$ between saturator and condenser.

\subsection{Upgraded mobility particle size spectrometers}

To evaluate the performance of upgraded mobility particle size spectrometers, several custom-built instruments from the EUSAAR/ACTRIS network were compared. The goal of this comparison was to understand the unit-to-unit variability of mobility particle size spectrometers obeying comparable technical standards under controlled laboratory conditions. We emphasize that all mobility particle size spectrometers under study were upgraded according to the technical harmonization described, with a long-term deployment at EUSAAR/ACTRIS measurement sites in mind.

Our results are based on a series of three intercomparison workshops conducted between 2006 and 2011 at the WCCAP facilities in Leipzig in the frame of the EUSAAR, ACCENT, ACTRIS, and WMO-GAW programs. The first workshop in November 2006 aimed to obtain the status of the comparability of all participating instrumentation, and to plan the technical harmonization of all instruments for high quality long-term size distribution measurements. During the second workshop in March 2008, we checked whether all instruments were correctly upgraded and what kind of discrepancies remained. After further improvements, a third intercomparison workshop was held in June 2009 to finally evaluate the comparability of the mobility particle size spectrometers, including commercial and custom-built instruments. Specific details of the mobility particle size spectrometers used during the third workshop are listed in Table A3 in Appendix A. Striving for a maximum comparability between instruments, we conducted a fourth intercomparison workshop in September-October 2011 including the three identical WCCAP reference mobility particle size spectrometers (IFT-REF-1, IFT-REF-2, and IFT-REF-3). 
In the following sections, results of the calibrations and intercomparisons of the third workshop are given describing the status of the mobility particle size spectrometers under laboratory conditions controlled by the individual users.

\subsubsection{Sizing accuracy using PSL particles}

A mandatory part of a performance check of a mobility particle size spectrometer concerns the sizing accuracy. This task can be accomplished using monodisperse spherical PSL (polystyrene latex) particles, whose diameters are certified by the manufacturer to be within $\pm 2.5 \%$ of the nominal diameter. For a DMA size check, monodisperse PSL particles of one or more sizes should be used (Mulholland et al., 2006). For practical reasons, we recommend to use at least $200 \mathrm{~nm}$ PSL particles: on one hand, a sufficient particle number concentration will remain after nebulization; while on the other hand, a minimum amount of residual material will usually be left on the surface of the particles after emerging from the aqueous suspension. Taking into account an additional minimum uncertainty of the sheath air flow rate of $\pm 1 \%$ for the individual spectrometers, and an uncertainty of $\pm 2.5 \%$ of the actual PSL size, we defined during the workshop that a maximum deviation of $\pm 3.5 \%$ from the nominal diameter of the PSL particles is tolerable for an instrument to pass the sizing quality test.

In practice, the nebulized PSL particles were pre-bipolarly charged using a custom-made bipolar diffusion charger $\left({ }^{85} \mathrm{Kr} ; 370 \mathrm{MBq}\right)$ and then fed into a well-mixed $0.5 \mathrm{~m}^{3}$ mixing chamber, which fed all mobility particle size spectrometers through equivalent connecting tubes. Mixing in the chamber was achieved with a fan. During the experiment, the resulting particle number concentration of PSL particles could be modified by changing the supply rate of dry, particle-free air into the chamber.

Inverted particle number size distributions of $200 \mathrm{~nm}$ PSL spheres are plotted in Fig. 4. As indicated above, the width of the measured PSL particle distribution depends mainly on the ratio of the aerosol to sheath air flow rate (see legend of Fig. 4) and on the standard deviation of the size of the PSL particles. The centroid diameters of all mobility particle size spectrometers were within the uncertainty range of $3.5 \%$. However, if the sheath air flows of all instruments were within $\pm 1 \%$, all peak diameters should be also within this range. However, it seems to be that there were uncertainties up to $\pm 3 \%$ of the sheath air flows. The TNO instrument clearly underestimated the $200 \mathrm{~nm}$ PSL size due to an erroneous sheath air flow rate, which we recognized and adjusted after the experiments.

\subsubsection{Particle number concentration and size distribution}

In a final step, the comparability of mobility particle size spectrometers was evaluated by simultaneous sampling of

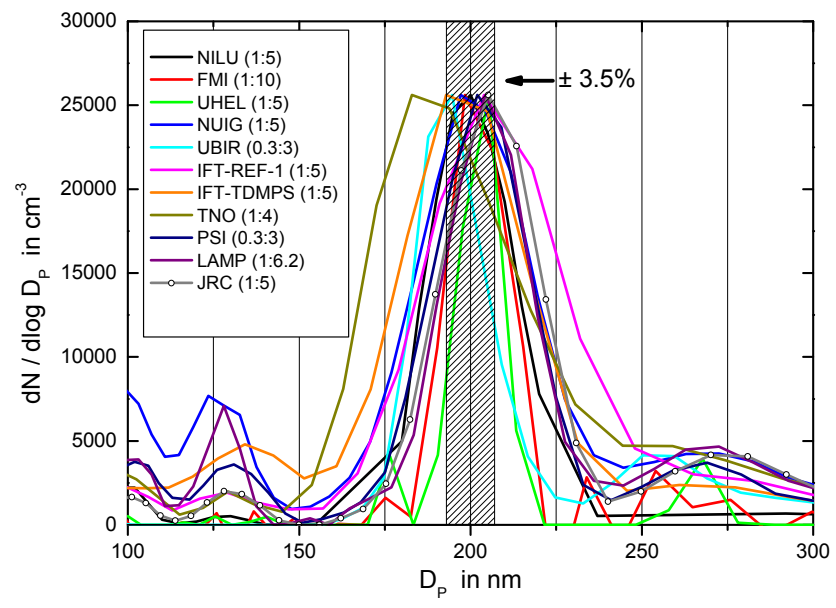

Fig. 4. PSL sphere $(200 \mathrm{~nm})$ measurements of the mobility particle size spectrometer to determine the sizing accuracy under laboratory conditions and controlled by the individual users. The size distributions are normalized to the peak concentration of the reference mobility particle size spectrometer. The $3.5 \%$ uncertainty range includes the uncertainties of the PSL particles from the nominal size $(2.5 \%)$ and the sheath air flow rate $( \pm 1 \%)$. The ratios given in the legend are aerosol to sheath air flow rate.

ambient aerosols. For the EUSAAR/ACTRIS network, the WCCAP built three "reference mobility particle size spectrometers" (IFT-REF-1, IFT-REF-2, and IFT-REF-3) dedicated to instrumental intercomparisons during laboratory workshops and on-site intercomparisons. The nomenclature "reference instrument" is not intended here to play the role of an absolute standard. An absolute standard for particle number concentration can only be defined by linkage to SI standards. Therefore, the WCCAP "reference instruments" are regarded as an intermediate comparison standard. As a second "reference instrument", particularly with regard to total particle number concentration, a total particle counter (CPC 3010 from TSI) with a standard saturator/condenser temperature difference of $17^{\circ} \mathrm{C}$ and flow rate of $11 \mathrm{~min}^{-1}$ was deployed.

Comparison experiments involved sampling ambient aerosols through the $0.5 \mathrm{~m}^{3}$ mixing chamber described above. All mobility particle size spectrometers sampled from this chamber through equivalent connecting tubes. Each participating group processed their electrical particle mobility distributions using their individual inversion routine. To take into account diffusional particle losses in the mobility particle size spectrometers, the standardized method of the "equivalent pipe length" was used as described above. All particle number size distributions shown in the following section are corrected for particle losses following this correction method.

We present results from run\# 4 of the third intercomparison workshop, since for this experiment, several instrumental problems were finally solved that had occurred before. 


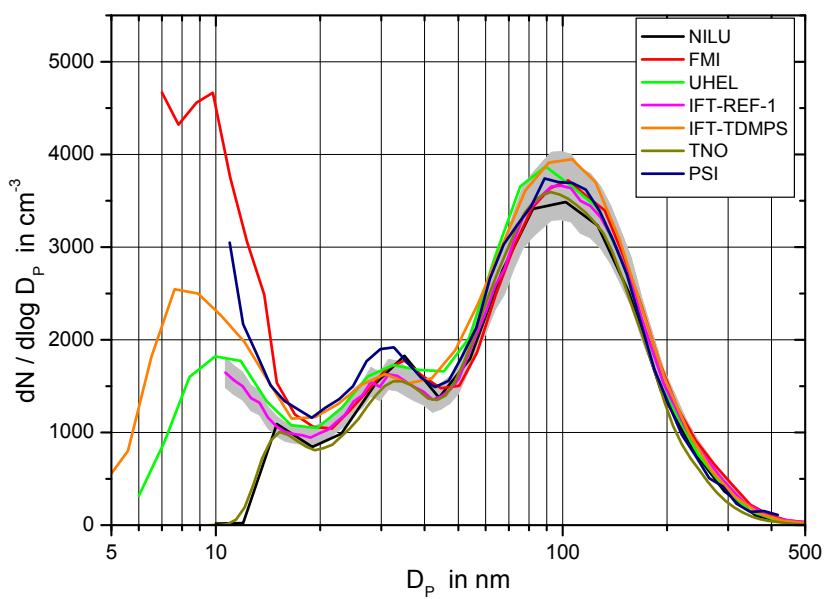

Fig. 5. Comparison of the ambient particle number size distributions of the different mobility particle size spectrometers against the reference mobility particle size spectrometer (IFT-REF-1). The shaded area marks the $\pm 10 \%$ range around IFT-REF-1. Internal particle losses in all instruments were corrected using the method of equivalent pipe length.

Unfortunately, however, not all mobility particle size spectrometer present in the workshop took part in run\# 4. Figure 5 shows the final particle number size distributions of ambient aerosol run\# 4. These particular periods were selected because (a) a maximum of instruments were available at this time and (b) the ambient particle number concentration showed limited variability.

The shaded area in Fig. 5 represents a $\pm 10 \%$ range around the particle number size distribution measured by the WCCAP reference mobility particle size spectrometer IFT-REF1. Visually, most of particle number size distributions agree from 20 to $200 \mathrm{~nm}$ within the shaded $\pm 10 \%$ range around IFT-REF-1. The two UHEL-DMPS and the IFT-TDMPS are slightly outside of this range. Also the PSI mobility size spectrometer is too high in the range below $40 \mathrm{~nm}$. Outside the $20-200 \mathrm{~nm}$ diameter range, the discrepancies increase. Two mobility particle size spectrometers were specifically designed to measure the particle number size distribution of nucleation mode particles (IFT-TDMPS and FMI) below $10 \mathrm{~nm}$ in diameter. They deviate however significantly below $10 \mathrm{~nm}$. The deviations below $20 \mathrm{~nm}$ mobility particle size spectrometers might be due to additional losses, which are not considered by the method of the equivalent pipe length. These uncertainties are investigated in the research infrastructure project ACTRIS. As found out later, the TNO and NILU spectrometers had problems with the high voltage power supply with an offset, we did not realize. This led to Zero or too low voltages for particles below $20 \mathrm{~nm}$ during this workshop.

Above $200 \mathrm{~nm}$, low counting statistics become an issue and the uncertainty range between the instruments obviously increases towards larger particle sizes. However, we were

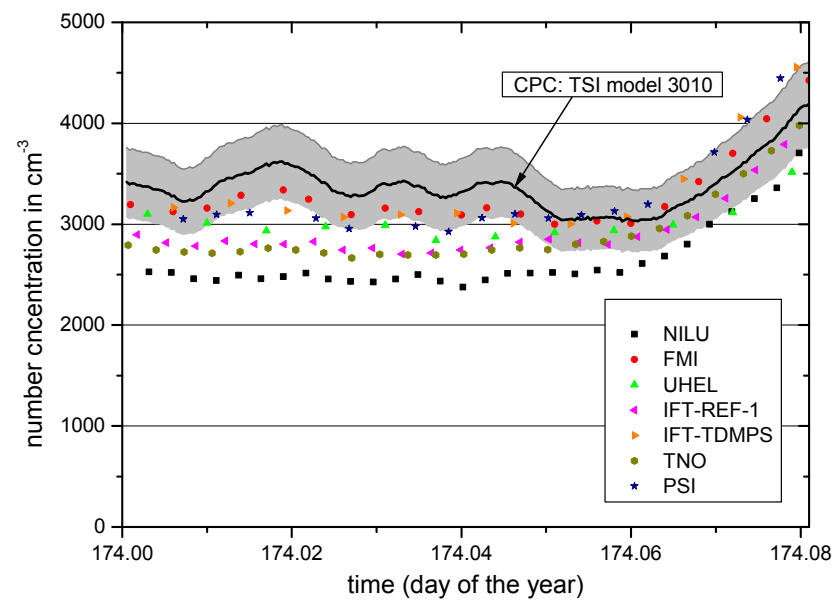

Fig. 6. Particle number concentration $>10 \mathrm{~nm}$ derived from ambient particle size distributions $(10-800 \mathrm{~nm})$ against a reference CPC (TSI model 3010). The shaded area marks the $\pm 10 \%$ range around the values of reference mobility particle size spectrometer (IFTREF-1). Note: day of year starts with 1 for 1 January at 00:00 LT.

not able to firmly evaluate the true reasons for the deviations at the upper end of the size distribution.

Figure 6 compares the integral particle number concentration of the mobility particle size spectrometers for particles $>10 \mathrm{~nm}$ with the value measured by the reference CPC (TSI model 3010). The shaded area represents the $\pm 10 \%$ range around the directly measure particle number concentration by the CPC. In the beginning of run\# 4 , the readings of the mobility particle size spectrometers fell below the reference CPC concentration. Our explanation is that a significant number of nucleation mode particles around $10 \mathrm{~nm}$ were present, which were only partially detected by the mobility spectrometers. Note: some mobility particle size spectrometers showed no sensitivity at all to particles $<15 \mathrm{~nm}$. After the nucleation mode particles disappeared, the particle number concentration of all instruments differed maximum $\pm 12 \%$ compared to the directly measured particle number concentration.

Figure 7 shows a comparison of the integral particle number concentrations larger than $100 \mathrm{~nm}$ for non-diffusive aerosol particles. The shaded area is the $\pm 10 \%$ range around the concentration given from IFT-REF-1. Particle number concentrations from all instruments agree within this range compared to IFT-REF-1. Note: the major number fraction is however contained in the size range 100-200 $\mathrm{nm}$.

Often, particle number size distributions are used to calculate properties of a higher moment of the size distribution, such as the surface area, volume, or mass concentration, or the light scattering coefficient. Increasing sizing and counting uncertainties in the particle number size distribution towards larger particles can lead to significant inaccuracies of these higher moments. In Fig. 8, we plot particle volume size 


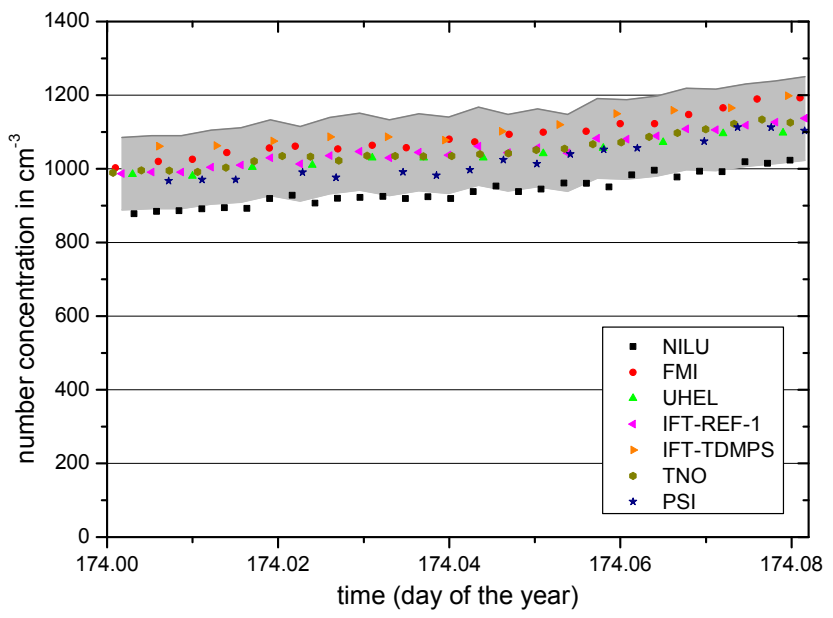

Fig. 7. Particle number concentration $>100 \mathrm{~nm}$ derived from ambient particle size distributions (100-800 nm) compared to the particle number concentration of the reference mobility particle size spectrometer (IFT-REF-1). The shaded area marks the $\pm 10 \%$ range around IFT-REF-1.

distributions derived from the particle number size distributions of run\# 4, assuming spherical particles. The shaded area represents a $\pm 20 \%$ range around the particle volume size distribution of IFT-REF-1. All mobility particle size spectrometers are within this $20 \%$ range at the volume peak $(250 \mathrm{~nm})$ except the TNO instrument $(\sim 40 \%)$. Towards the end of the size range, the discrepancy of two mobility particle size spectrometers increases up to $70 \%$ compared to IFT-REF-1. Since there is no absolute standard of particle volume size distribution, we cannot really judge the correct value. We re-run the data with the IFT-inversion routine, but this did not significantly improve the values. The multiple charge correction used in the inversion programs does not seem to be the problem. One reason can be that the bipolar charge equilibrium was not completely reached. However, we are not able to firmly conclude what the underlying reasons for the observed divergences are. On the other hand, mobility particle size spectrometers are not designed to determine the volume distribution.

\subsection{Connection of the reference mobility particle size spectrometers to the total particle number concentration}

Missing, at this point, is the link between the three WCCAP reference mobility particle size spectrometers and a total particle number concentration measured by an independent standard. To evaluate the performance of the reference mobility particle size spectrometers with respect to particle number concentration, a fourth intercomparison workshop was carried out in the frame of ACTRIS in September/October 2011. We compared the three reference mobility particle size spectrometers of the WCCAP (IFT-REF-1,

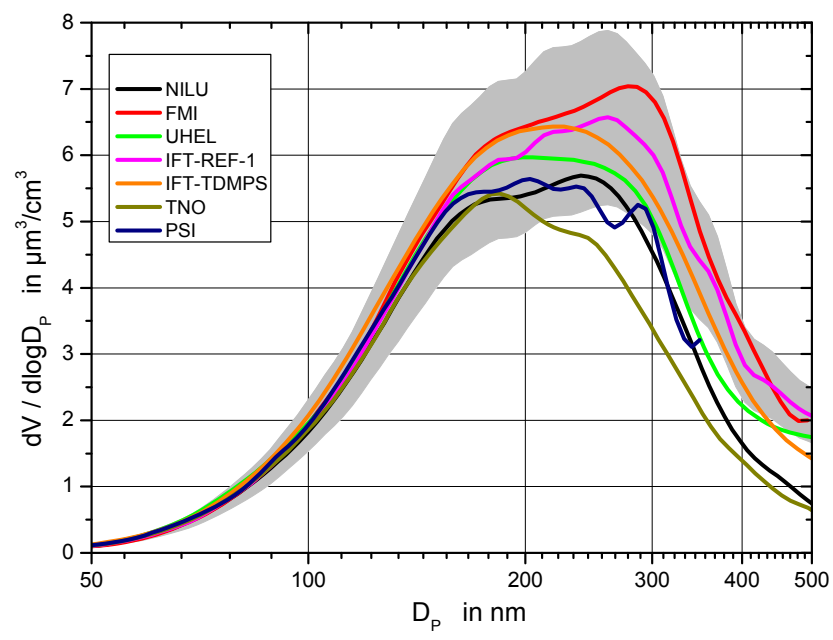

Fig. 8. Intercomparison of the ambient volume particle size distribution of the mobility particle size spectrometers. The shaded area marks the $\pm 10 \%$ range around the reference mobility particle size spectrometer (IFT-REF-1).

IFT-REF-2, and IFT-REF-3). Again, the nomenclature "reference instrument" is not meant as an absolute standard. As a reference detector for total particle number concentration, a CPC (TSI model 3772) was used. This condensation particle counter was calibrated against an aerosol electrometer during the international CPC intercomparison workshop at the WCCAP facility in September 2011. This aerosol electrometer was calibrated against to a well-known femto-Ampere source at PTB (Physikalisch Technische Bundesanstalt), the German National Metrology Institute. The particle number concentration could be thus related to an SI-unit. The $50 \%$ counting efficiency diameter of this CPC was determined to approximately $8 \mathrm{~nm}$.

Figure 9 shows inverted ambient particle number size and volume size distributions as measured by the three WCCAP reference mobility particle size spectrometers (IFT-REF-1, IFT-REF-2, and IFT-REF-3) in the period from 28 September 2011, 20:00 LT to 29 September 2011, 07:00 LT. We calibrated all flow rates with extreme care, and confirmed that the sizing accuracy of the instruments was within $\pm 2 \%$ of the nominal PSL $(200 \mathrm{~nm})$ particle size. All particle number size distributions include the correction for diffusional losses using the method of equivalent pipe length. The maximum deviation of all different mobility particle size spectrometers was found to be $\pm 5 \%$ from the average at the number peak of the size distribution. The light grey shaded area represents the $\pm 10 \%$ range around the average of the three mobility particle size spectrometers. Additionally, we plotted the calculated volume size distributions of all mobility particle size spectrometers. The dark grey shaded area is again the $\pm 10 \%$ range around the average of all systems. All mobility particle size spectrometers are within this range. This unit-tounit variability of these technical identical mobility particle 


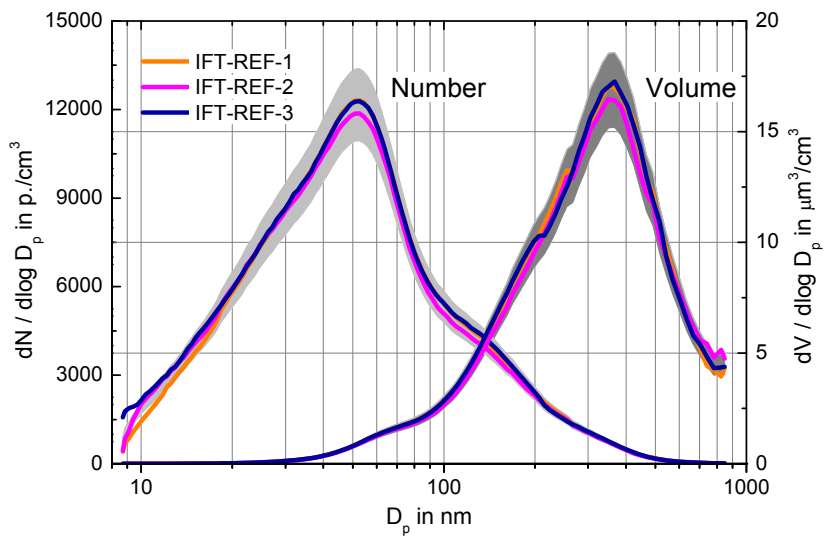

Fig. 9. Ambient particle number and volume size distributions measured by the three WCCAP reference mobility particle size spectrometers (IFT-REF-1, IFT-REF-2 and IFT-REF-3). The particle number size distributions include all corrections for internal particle losses using the method of equivalent pipe length.

size spectrometers represents the accuracy that we are able to achieve the current state of knowledge and technology under controlled laboratory conditions.

Figure 10 shows the comparison of the ambient particle number concentration derived from three reference instruments (size range 10-800 $\mathrm{nm}$ and diffusion loss correction) and the reference counter (CPC 3772) (28 September 2011, 20:00 LT -29 September 2011, 07:00 LT). This time series shows a close correspondance of the signal for all instruments. During certain time periods, the CPC 3772 exceeded however the integral particle number concentration of the three mobility particle size spectrometers. This might have been during periods with increased particle number concentrations around $10 \mathrm{~nm}$ particle size. Overall, the exemplary scatter diagram (Fig. 11) reveals a close linear relationship (slope $=0.97, R^{2}=0.97$ ) of the CPC 3772 and IFT-REF-1 after correction for coincidence and diffusional losses, respectivley.

A suspected source of uncertainty in the comparison of the mobility particle size spectrometer and a CPC seems to be at the lower end of particle number size distribution. To alleviate effects at the lower end of the particle size distribution, a package of 30 diffusion screens (traditionally used in a diffusion battery) was employed to efficiently remove particles especially at the lower tail of the ambient particle number size distribution. Therefore, the IFT-REF-2 and the CPC 3772 were set up to sample through this package of 30 diffusion screens. The effect of the 30 diffusion screens can be seen in Fig. 12. The solid black line represents the ambient particle number size distribution measured with the IFT-REF-1 system, while the dashed line shows the particle number size distribution of IFT-REF-2 sampled through the 30 diffusion screens. Particles below $25 \mathrm{~nm}$ in size are efficiently removed. Figure 13 shows the comparison between

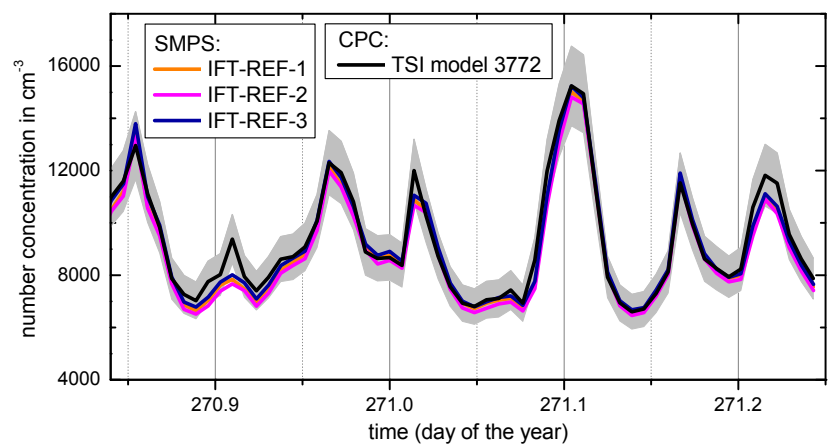

Fig. 10. Comparison of the ambient particle number concentration derived from three WCCAP reference mobility particle size spectrometers (10-800 nm) and a CPC (TSI model 3772). The particle number size distribution and CPC data were corrected for internal losses using the method of equivalent pipe length and coincidence, respectively.

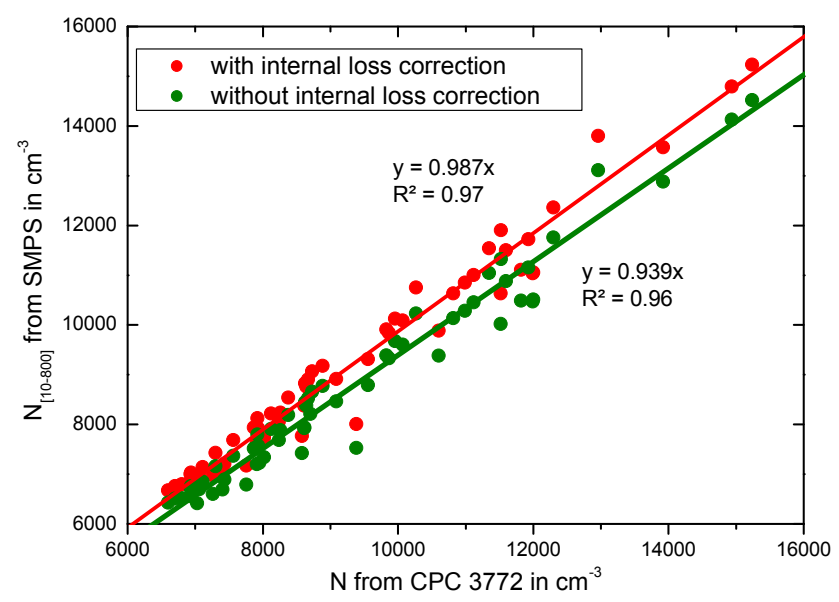

Fig. 11. Scatter diagram of the ambient particle number concentration of the experiment in Fig. 10 derived from the mobility particle size spectrometer IFT-REF-1 $(10-800 \mathrm{~nm})$ and directly measured by a CPC (TSI model 3772). The open and solid circles represent the correlation without (slope $=0.939 ; R^{2}=0.96$ ) and with corrections (slope $=0.987 ; R^{2}=0.97$ ), respectively, for coincidence and internal diffusional losses using the method of equivalent pipe length.

the total particle number concentration of IFT-REF- 2 and the CPC (TSI model 3772). The correspondance between IFTREF-2 and CPC particle number concentrations was found to be almost ideal. The slope of the linear interpolation was 1.012 with a $R^{2}$ of 0.996 . These result confirms that the WCCAP reference mobility particle size sprectrometers are reliable instruments to perform the quality assurance of particle number size distributions in observational networks.

Based on the experience of the intercomparison workshops, we conclude that the instrumental uncertainties presented in this study can be regarded as a lower limit for the 


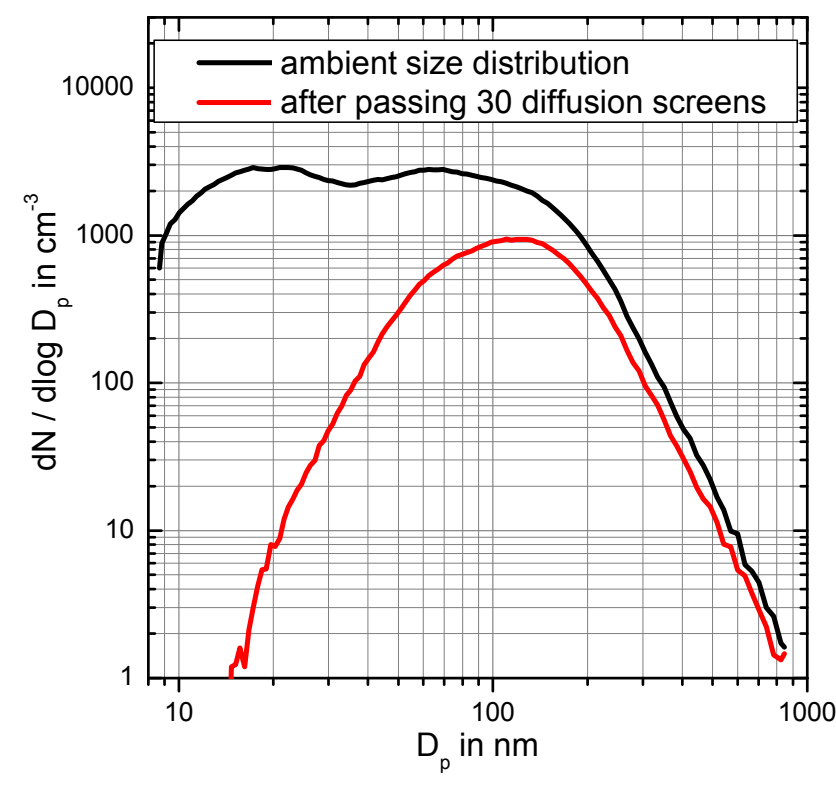

Fig. 12. Ambient particle number size distribution before (solid line; IFT-REF-1) and after a package of 30 diffusion screens (dashed line; IFT-REF-2) to minimize the influence of the highly time-variable particle number concentration of particles smaller than $30 \mathrm{~nm}$.

uncertainties encountered in long-term field measurements. Considering the span of environmental conditions found at the variety of field stations in operation, it is likely that effects relating to, e.g. temperature and humidity fluctuations in the field laboratories, instabilities in line power, differences in atmospheric pressure, the lower degree of maintenance as compared to the laboratory workshops, and changes to the instrumentation during their transport to remote locations might add up to uncertainties that affect the comparison of global atmospheric data. While many of the latter effects can probably not be entirely avoided, it appears even more crucial to ensure a homogeneous technical standard of the instrumentation, which is a matter that can be well planned in advance. Consequently, we recommend standard operating procedures described in Appendix A1. The quality of ambient particle number size distribution measurements can only then be expected to fall within the range of uncertainty determined in the work here.

\section{Traceability of mobility particle size spectrometer data}

In the EMEP data base (called "EBAS"), particle number size distributions have traditionally been stored as hourly average concentrations for standard temperature $(273.15 \mathrm{~K})$ and pressure $(1013.25 \mathrm{hPa})$. Because of the previous lack of harmonization of the multiple charge inversion routines as well as subsequent correction procedures, the quality and

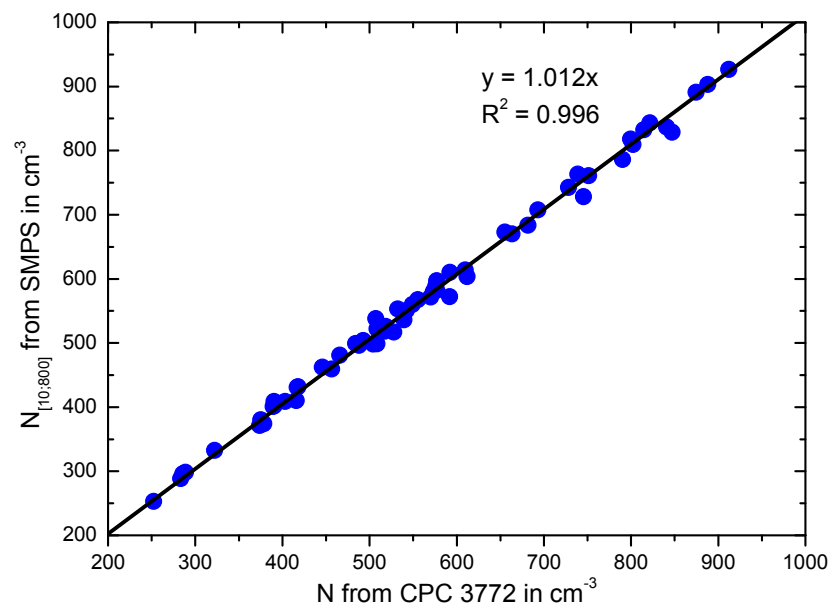

Fig. 13. Scatter diagram of the ambient particle number concentration passed through 30 diffusion screens. The correlation between the mobility particle size spectrometer IFT-REF-2 $(10-800 \mathrm{~nm})$ and a CPC (TSI model 3772) is almost ideal. The solid circles represent the correlation with internal diffusional losses (slope $=1.012$; $R^{2}=0.996$ ) using the method of equivalent pipe length.

level of data corrections of the previously published data sets is poorly known. Traceability of the data and evaluation of uncertainties are only possible if the data originators supply raw mobility distributions, system parameters, and documentation of the data evaluation steps along with the final measurement data.

To encourage such a traceability of measurement data, an extended data structure for particle number size distribution measurements was developed within EUSAAR/ACTRIS. The new structure consists of three levels, basically representing "raw", "intermediate", and "final" data. "Raw" encompasses raw values measured directly by the instrument, including instrumental status parameters not processed through any data analysis or inversion software. "Intermediate" contains particle number size distributions at the maximum time resolution, and after applying multiple charge inversions and all instrumental corrections. "Final" adds averaging to hourly values and standardization to standard condition of $273.15 \mathrm{~K}$ and $1013.25 \mathrm{hPa}$. At all stages, metadata, which contain extended descriptions and qualifiers of the data, are included. The three-level structure was designed to ensure traceability of published measurement data back to their instrumental origins.

Besides the traceability of measurement data and the harmonization of their quality assurance procedures, a number of additional objectives were kept in mind when defining the data structure and file formats:

- The data format should be suitable for nearreal-time transmission to archives, such as the EUSAAR/ACTRIS data center (EBAS) and the WMO GAW-WDCA (World Data Centre for Aerosols) 
hosted at NILU (Norwegian Institute for Air Research). This is intended as a first step towards including aerosol data in online information systems.

- The format should collect all instrument metadata so that they can be stored and archived together with the raw data, to allow for future reprocessing of the data similar to procedures already implemented for satellite observation data.

- To ease the adaptation to the new format by the data originators, it is defined to allow for gradual implementation, i.e. it distinguishes between compulsory and optional parameters.

A detailed description of the data formats for the three levels (raw, intermediate, and final) is provided in Appendix A4. A description of how the data were processed should be given, either in an additional "read-me" file or in the commenting part of the metadata.

The DMA dimensions (rod diameter and cylinder inner diameter and length), the nominal sheath and aerosol (and $\mathrm{CPC}$ ) flow rates, and possibly the serial numbers of the DMA and CPC should be supplied in the metadata.

\section{Summary}

This work summarizes new experimental evidence from the intercomparison of custom-built as well as commercial mobility particle size spectrometers (e.g. SMPS, DMPS, TDMPS), and provides recommendations to harmonize the instrumental standards and modes of operation of such measurements, including data evaluation and reporting.

In the framework of the European research infrastructure projects EUSAAR/ACTRIS, we standardized the technical set-up of mobility particle size spectrometers for long-term observations. This standard set-up includes a recommendation to control, measure, and store all relevant system parameters, such as the flow rate, temperature, relative humidity in the aerosol and sheath air streams, and the absolute pressure close to the DMA. The relative humidity in the aerosol and sheath air should be kept below $40 \%$ at all times. Drying of the aerosol sample flow is usually required if the dew point temperature exceeds $10^{\circ} \mathrm{C}$ and the room temperature is kept to approximately $20-25^{\circ} \mathrm{C}$. Note: if the dew point temperature is occasionally higher than the room temperature, the inlet flow has to be dried before entering the room.

Certain system checks and calibrations have to be done frequently to allow long-term operation of mobility particle size spectrometers at field stations, as listed in the standard operation procedures in the Appendix A1. Most important are regular system maintenance, checks and calibration of the flow sensors, checking of the sizing accuracy by PSL particles, and comparisons against a reference mobility particle size spectrometer. Furthermore, proper function of the condensation particle counter, including the counting efficiency, has to be checked at least once per year.

It is also recommended to use common constants and equations determining the electrical mobility for the measurement and the bipolar charge distribution needed to convert the measured mobility charge distribution into the particle number size distribution. These constants and equations follow the recommendations of the new ISO standard 15900.

We compared different commercial and customprogrammed inversion routines that calculate, from a given set of electrical particle mobility distributions, the final particle number size distribution for an ideal transfer function, without correction for particle losses in the system. Most of inversion routines seem to perform in a similar fashion, with maximum deviations of $5 \%$ with respect to individual sections of the particle number size distribution. Deviations in the particle number size distribution between individual mobility particle size spectrometers are thus not attributable to the inversion programs.

In a series of intercomparison workshops, the range of uncertainty among commercial and custom-built mobility particle size spectrometers was determined. All participating systems were upgraded to the recommended set-up and operated by experienced users. We recommended a common procedure for the correction of diffusional particle losses in the mobility particle size spectrometers. The conclusion is that we can reach uncertainties around $10 \%$ with state-ofthe-art mobility particle size spectrometers for the size range between 20 and $200 \mathrm{~nm}$ in particle size. For smaller particle sizes, the deviations become significantly greater. Divergences at the upper end of the size spectrum $(300-800 \mathrm{~nm})$ were also observed. At present, the underlying reasons for these deviations are not well understood.

We demonstrated that the WCCAP reference mobility particle size spectrometers can be closely connected to calibrated condensation particle counters. These reference instruments can thus be used for quality assurance programs in atmospheric observational networks.

We developed a new three-level data submission protocol for particle number size distribution data, which is implemented in the EBAS data base (EMEP and GAW). Level-0 data contain electrical particle mobility distribution data and system parameters as given above. The electrical particle mobility distribution should be provided as an array of particle number concentrations versus particle diameters (electrical particle mobility for singly charged particles). Level-1 data are particle number size distributions as calculated after inversion and correction for particle losses (temperature, pressure and time resolution as measured). In level-2, the particle number size distributions are given as hourly averages corrected to standard temperature $(273.15 \mathrm{~K})$ and pressure $(1013.25 \mathrm{hPa})$.

The technical standards and data protocols presented in this investigation have been implemented in mobility particle 
size spectrometer measurements in a number of observational networks. These include EUSAAR/ACTRIS (Asmi et al., 2011), the Nordic Aerosol Network (Tunved et al., 2003), the German Ultrafine Aerosol Network (Birmili et al., 2009), and parts of the GAW network.

The goal of these recommendations is that world-wide mobility particle size spectrometer measurements become more standardized and comparable, which adds to the reliability and usefulness of the global surface-based atmospheric observation network. Another goal is to set a standard, which can be adopted by manufactures and applied in commercial mobility particle size spectrometers.

\section{Appendix A}

\section{Supporting information}

\section{A1 Standard operation procedure for calibrations and system checks for mobility particle size spectrometers}

For long-term mobility particle size spectrometer measurements, we recommend the following listed items to improve the quality of the measurements.

- Pressure transducers employed to measure the aerosol flow rate or mass flow meters used to determine the sheath air flow rate have to be calibrated at least twice a year. The aerosol and sheath air flow rates should be regularly measured once per month with an independent flow standard such as an electrical bubble flow. The reference standard should have a low pressure drop. The flow rate at the pressure within the DMA should be determined.

- In case of a closed-loop instrument, the pump/blower must be sealed and leak testing should be part of the regular maintenance schedule for the instrument.

- Humidity and temperature sensors for the aerosol and sheath air flow have to be checked prior to their deployment and afterwards at least once per year.

- The response function of the high voltage (HV) supply should be calibrated. This should include the analogue output module, if high voltage supply is controlled through an analogue voltage. The calibration function of the high voltage should be implemented into the scanning software or the data analysis. Correct sizing of small particles is highly sensitive to accurate knowledge of the applied HV. Particular care is hence required in the low voltage range. A HV-probe with ultralow impedance should be used here. The HV power supply has to be checked monthly.
- Furthermore, CPCs have to be calibrated regularly at least once per year to detect malfunctions such as degradation of the laser diode, temperature instabilities, or internal pollution. CPCs should be only used after determining the flow rate and after a calibration of the detection efficiency curve (see also Wiedensohler et al., 1997) and the plateau detection efficiency. Often, the CPC flow rate is controlled by a critical orifice. It should not differ more than few percent from the nominal value. The deviation of the flow rate from the nominal value should then be taken into account in the calculation of the particle number size distribution. The volume flow rate should be checked on a monthly basis.

- The sizing accuracy of mobility particle size spectrometers have to be verified using $200 \mathrm{~nm}$ PSL spheres frequently. The use of $200 \mathrm{~nm}$ PSL particles is a compromise obtaining a sufficient particle number concentration and a minimum of residual material on the particles. The measured peak diameter should be within the nominal uncertainties of the PSL spheres $( \pm 2.5 \%)$ and the sheath air flow rate $( \pm 1 \%)$. Due to a pressure drop over the external volumetric flow meter, it is often difficult to precisely measure the actual flow rate of the sheath air. In this case, the sheath air flow rate might be slightly adjusted by few percent to match the nominal PSL sphere size.

- For scanning mobility particle size spectrometers, an incorrect pluming time can only be determined by the PSL sphere check. The pluming time is correct if up- and down-scans show the same result. The scan time has to be long enough because of the slow CPC response and to avoid smearing effects. We recommend an up- or down-scan time of minimum 2 min.

- Mobility particle size spectrometers should also be regularly compared to a reference instruments for a period of few days once per year (if a reference system is available). This intercomparison can be done either within an intercomparison workshop or at the sampling site. If a reference mobility particle size spectrometer is not available, also the total particle number concentration measured by a CPC can be compared to the number integral of the size distribution. The integral of the particle number size distribution should be compared to the directly measured total particle number concentration if no nucleation mode particles are present. Ideally, the difference in particle number concentrations should be smaller than $10 \%$ after correction for internal diffusional losses.

- The Zero-check of the system should be also done every month. An absolute particle filter should be connected to the system inlet and scanned for several size distributions. Ideally, the background should be close to zero. 
Table A1. Flag list for data of mobility particle size spectrometer measurements according to the EMEP flagging description.

\begin{tabular}{|c|c|c|}
\hline Flag & $\begin{array}{l}\text { Original description/commentary - } \\
\text { EMEP data base }\end{array}$ & $\begin{array}{l}\text { Comments especially for } \\
\text { mobility spectrometers }\end{array}$ \\
\hline \multicolumn{3}{|c|}{ Missing data } \\
\hline 999 & $\begin{array}{l}\text { MMU I } \\
\text { Missing measurement, unspecified reason }\end{array}$ & $\begin{array}{l}\text { Instrument not operational } \\
\text { False measurements }\end{array}$ \\
\hline 980 & $\begin{array}{l}\text { MZS I } \\
\text { Missing due to calibration or zero check }\end{array}$ & $\begin{array}{l}\text { E.g. zero check with total particle } \\
\text { filter or HV power supply off }\end{array}$ \\
\hline \multicolumn{3}{|c|}{ Mechanical problems } \\
\hline 699 & $\begin{array}{l}\text { LMU I } \\
\text { Mechanical problem, unspecified reason }\end{array}$ & $\begin{array}{l}\text { E.g. problems with flow, leaks, or } \\
\text { HV supply }\end{array}$ \\
\hline 662 & $\begin{array}{l}\text { LFV V } \\
\text { Too high sampling flow, data considered valid }\end{array}$ & $\begin{array}{l}\text { E.g. aerosol flow or sheath flow } \\
\text { rate out of range but considered as } \\
\text { valid }\end{array}$ \\
\hline 652 & $\begin{array}{l}\text { LCN V } \\
\text { Construction/activity nearby }\end{array}$ & $\begin{array}{l}\text { Disturbance by other laboratory } \\
\text { activity }\end{array}$ \\
\hline \multicolumn{3}{|c|}{ Extreme or inconsistent values } \\
\hline 499 & $\begin{array}{l}\text { INU V } \\
\text { Inconsistent with another unspecified } \\
\text { measurement }\end{array}$ & $\begin{array}{l}\text { E.g. inconsistency with total } \\
\text { particle counter reading }\end{array}$ \\
\hline 459 & $\begin{array}{l}\text { EUE I } \\
\text { Extreme value, unspecified error }\end{array}$ & $\begin{array}{l}\text { Unexplained extreme values, } \\
\text { technical problem is suspected }\end{array}$ \\
\hline 410 & $\begin{array}{l}\text { SDE V } \\
\text { Sahara dust event }\end{array}$ & \\
\hline \multicolumn{3}{|c|}{ Flags for aggregated data sets } \\
\hline 394 & $\begin{array}{l}\text { DC9 V } \\
\text { Data completeness less than } 90 \%\end{array}$ & \\
\hline 392 & $\begin{array}{l}\text { DC7 V } \\
\text { Data completeness less than } 70 \%\end{array}$ & \\
\hline 390 & $\begin{array}{l}\text { DC5 V } \\
\text { Data completeness less than } 50 \%\end{array}$ & \\
\hline \multicolumn{3}{|c|}{ Exception flags for accepted, irregular data } \\
\hline 189 & $\begin{array}{l}\text { LCS V } \\
\text { possible local contamination indicated by wind } \\
\text { from contaminated sector (auto) }\end{array}$ & \\
\hline 188 & $\begin{array}{l}\text { LCW V } \\
\text { possible local contamination indicated by low } \\
\text { wind speed (auto) }\end{array}$ & \\
\hline 187 & $\begin{array}{l}\text { LCP V } \\
\text { possible local contamination indicated by } \\
\text { occurrence of new particles (auto) }\end{array}$ & \\
\hline 186 & $\begin{array}{l}\text { LCA V } \\
\text { possible local contamination indicated by single } \\
\text { scattering albedo (auto) }\end{array}$ & \\
\hline
\end{tabular}


Table 2. Descriptions of the different non-commercial inversion routines to calculate particle number size distributions from mobility particle size spectrometer measurements.

\begin{tabular}{|c|c|c|c|}
\hline & Transfer function & $\begin{array}{l}\text { Multiple charge } \\
\text { correction }\end{array}$ & $\begin{array}{l}\text { Interpolation (new sampling } \\
\text { points/bins) }\end{array}$ \\
\hline IFT & Ideal transfer probability & Wiedensohler (1988) & $\begin{array}{l}\text { Linear } \\
\text { (no new discretizing) }\end{array}$ \\
\hline $\begin{array}{l}\text { NILU } \\
\text { (Fiebig et al., 2005) }\end{array}$ & Stolzenburg (1988) & Wiedensohler (1988) & $\begin{array}{l}\text { Yes } \\
\text { (finer discretizing) }\end{array}$ \\
\hline UHEL/FMI & Stolzenburg (1988) & Wiedensohler (1988) & Not available \\
\hline PSI & Real transfer probability & Wiedensohler (1988) & $\begin{array}{l}\text { Yes } \\
\text { (discrete logarithmic } \\
\text { equidistant bins, } 2^{n} \\
\text { per decade) }\end{array}$ \\
\hline $\begin{array}{l}\text { ULUND } \\
\text { (Zhou, 2001) }\end{array}$ & Real transfer probability & Wiedensohler (1988) & $\begin{array}{l}\text { Spline } \\
\text { (discrete logarithmic } \\
\text { equidistant bins) }\end{array}$ \\
\hline ISAC & Real transfer probability & Wiedensohler (1988) & $\begin{array}{l}\text { Cubic or linear spline } \\
\text { (discrete logarithmic } \\
\text { equidistant bins) }\end{array}$ \\
\hline LAMP & $\begin{array}{l}\text { Ideal transfer function } \\
\text { (triangle) }\end{array}$ & Wiedensohler (1988) & Not available \\
\hline JRC & $\begin{array}{l}\text { Ideal transfer function } \\
\text { (triangle) }\end{array}$ & $\begin{array}{l}\text { Wiedensohler } \\
(1988)\end{array}$ & $\begin{array}{l}\text { Linear spline } \\
\text { (discrete logarithmic } \\
\text { equidistant bins) }\end{array}$ \\
\hline UMN & $\begin{array}{l}\text { Stolzenburg and McMurry } \\
\text { (2008) }\end{array}$ & $\begin{array}{l}\text { Wiedensohler (1988) } \\
\text { and Fuchs charging theory } \\
\text { (Fuchs, 1963; Hoppel and Frick, 1986) }\end{array}$ & Not available \\
\hline PKU & Ideal transfer function & Wiedensohler (1988) & Linear spline in scale of $\log \mathrm{Dp}$ \\
\hline $\begin{array}{l}\text { TNO (IFT } \\
\text { inversion) }\end{array}$ & Real transfer probability & Wiedensohler (1988) & $\begin{array}{l}\text { Linear spline (discrete } \\
\text { logarithmic equidistant bins) }\end{array}$ \\
\hline $\begin{array}{l}\text { UBIR (TSI } \\
\text { inversion } \\
\text { routine) }\end{array}$ & Ideal transfer function & Wiedensohler (1988) & TSI inversion routine \\
\hline
\end{tabular}

\section{A2 Description of non-commercial inversion routines}

In Table $\mathrm{A} 2$, the inversion routines of the different noncommercial mobility particle size spectrometers are described in detail.

\section{A3 Description of the mobility particle size spectrometers}

In Table A3, the technical set up and software of the different non-commercial mobility particle size spectrometers are described in detail.

\section{A4 EBAS Three-level data structure}

\section{A4.1 Level-0}

The level-0 data set contains the metadata of the mobility particle size spectrometer, all mandatory raw data, and system parameters, as well as optional status parameters.

- Metadata should be included in the header as comment lines describing the mobility particle size spectrometer (e.g. inlet type, inlet length and diameter, DMA types, DMA dimensions, CPC type, serial numbers, dryer type, etc.), operational settings 
Table 3. Description of the mobility particle size spectrometers used in the third intercomparison workshop.

\begin{tabular}{|c|c|c|}
\hline & & Description \\
\hline \multirow{10}{*}{$\begin{array}{l}\text { IFT-SMPS } \\
\text { IFT-REF-1 } \\
\text { IFT-REF-2 } \\
\text { IFT-REF-3 }\end{array}$} & Range: & $10-800 \mathrm{~nm}$ \\
\hline & \multirow[t]{2}{*}{ DMA: } & Hauke-type (custom-made); inner diameter $50 \mathrm{~mm}$, outer \\
\hline & & diameter $67 \mathrm{~mm}$, length $280 \mathrm{~mm}$ \\
\hline & \multirow{2}{*}{$\begin{array}{l}\text { Bipolar diffusion charger: } \\
\text { CPC: }\end{array}$} & ${ }^{85} \mathrm{Kr}$ (non-commercial) \\
\hline & & TSI model $3010, \Delta T=17 \mathrm{~K}$ \\
\hline & Software: & IFT scanning program \\
\hline & Sheath air flow: & $\begin{array}{l}\text { Closed-loop system with blower, heat exchanger, mass } \\
\text { flow meter, and Nafion dryer }\end{array}$ \\
\hline & Aerosol flow: & $\Delta p$ capillary for volumetric flow and Nafion dryer \\
\hline & Sensors: & $T, \mathrm{RH}$ in aerosol and sheath air flows; $p$ in aerosol flow \\
\hline & HV power supply: & Positive \\
\hline \multirow[t]{16}{*}{ IFT-TDMPS } & Range: & $3-800 \mathrm{~nm}$ \\
\hline & DMA: & $\begin{array}{l}\text { Hauke-type (custom-made); inner diameter } 50 \mathrm{~mm} \text {, outer } \\
\text { diameter } 67 \mathrm{~mm} \text {, length } 280 \mathrm{~mm}\end{array}$ \\
\hline & UDMA (Ultrafine DMA): & $\begin{array}{l}\text { Hauke-type; inner diameter } 50 \mathrm{~mm} \text {, outer diameter } \\
67 \mathrm{~mm} \text {, length } 110 \mathrm{~mm}\end{array}$ \\
\hline & \multirow{2}{*}{$\begin{array}{l}\text { Bipolar diffusion charger: } \\
\text { CPC: }\end{array}$} & ${ }^{85} \mathrm{Kr}$ (non-commercial) \\
\hline & & TSI model $3010, \Delta T=17 \mathrm{~K}$ \\
\hline & UCPC (Ultrafine CPC): & TSI model $3025, \Delta T=27 \mathrm{~K}$ \\
\hline & Software: & IFT stepping program \\
\hline & Sheath air flow DMA: & $\begin{array}{l}\text { Closed-loop system with blower, heat exchanger, mass } \\
\text { flow meter, and Nafion dryer }\end{array}$ \\
\hline & Aerosol flow DMA: & $\Delta p$ capillary for volumetric flow and Nafion dryer \\
\hline & Sensors DMA: & $\begin{array}{l}T, \mathrm{RH} \text { in aerosol and sheath air flows; } p \text { in aerosol flow } \\
\text { Positive }\end{array}$ \\
\hline & \multirow{3}{*}{$\begin{array}{l}\text { HV power supply DMA: } \\
\text { Sheath air flow UDMA: }\end{array}$} & Closed-loop system with blower, heat exchanger, mass \\
\hline & & flow meter, and Nafion dryer \\
\hline & & $\Delta p$ capillary for volumetric flow and Nafion dryer \\
\hline & \multirow{3}{*}{$\begin{array}{l}\text { Aerosol flow UDMA: } \\
\text { Sensors UDMA: } \\
\text { HV power supply UDMA: }\end{array}$} & $T, \mathrm{RH}$ in aerosol and sheath air flows \\
\hline & & Positive \\
\hline & & \\
\hline \multirow[t]{9}{*}{$N I L U-D M P S$} & Range: & $10-550 \mathrm{~nm}$ \\
\hline & DMA: & $\begin{array}{l}\text { Hauke-type (custom-made); inner diameter } 50 \mathrm{~mm} \text {, outer } \\
\text { diameter } 67 \mathrm{~mm} \text {, length } 280 \mathrm{~mm}\end{array}$ \\
\hline & \multirow{4}{*}{$\begin{array}{l}\text { Bipolar diffusion charger: } \\
\text { CPC: } \\
\text { Software: } \\
\text { Sheath air flow: }\end{array}$} & ${ }^{63} \mathrm{Ni}($ non-commercial) \\
\hline & & TSI model $3010, \Delta T=25 \mathrm{~K}$ \\
\hline & & NILU stepping program \\
\hline & & $\begin{array}{l}\text { Closed-loop system with blower, mass flow meter, heat } \\
\text { exchanger, and Nafion dryer }\end{array}$ \\
\hline & \multirow{3}{*}{$\begin{array}{l}\text { Aerosol flow: } \\
\text { Sensors: } \\
\text { HV power supply: }\end{array}$} & Nafion dryer \\
\hline & & $T, \mathrm{RH}, p$ in aerosol and sheath air flows \\
\hline & & Positive \\
\hline \multirow[t]{10}{*}{ UHEL-DMPS } & Range: & $6-800 \mathrm{~nm}$ \\
\hline & DMA: & $\begin{array}{l}\text { Hauke-type (custom-made); inner diameter } 50 \mathrm{~mm} \text {, outer } \\
\text { diameter } 67 \mathrm{~mm} \text {, length } 280 \mathrm{~mm}\end{array}$ \\
\hline & \multirow{2}{*}{$\begin{array}{l}\text { Bipolar diffusion charger: } \\
\text { CPC: }\end{array}$} & ${ }^{14} \mathrm{C}$ (non-commercial) \\
\hline & & TSI model $3772, \Delta T>25 \mathrm{~K}$ \\
\hline & Software: & UHEL stepping program \\
\hline & Sheath air flow: & $\begin{array}{l}\text { Closed-loop system with blower, heat exchanger, } \\
\text { volumetric flow meter }\end{array}$ \\
\hline & Aerosol flow: & $\Delta p$ capillary for volumetric flow and Nafion dryer \\
\hline & Sensors: & $T, \mathrm{RH}$ in aerosol flow; $T, p$ in sheath air flow \\
\hline & HV power supply: & Positive \\
\hline & Extra: & $\begin{array}{l}\text { Possibility to switch between two DMA aerosol and } \\
\text { sheath air flow rates }\end{array}$ \\
\hline
\end{tabular}


Table A3. Continued.

\begin{tabular}{|c|c|c|}
\hline & & Description \\
\hline \multirow[t]{10}{*}{$P S I-S M P S$} & Range: & $10-450 \mathrm{~nm}$ \\
\hline & DMA: & TSI modified-type (custom-made); inner diameter \\
\hline & & $18.8 \mathrm{~mm}$, outer diameter $39.2 \mathrm{~mm}$, length $437 \mathrm{~mm}$ \\
\hline & Bipolar diffusion charger: & ${ }^{85} \mathrm{Kr}$ (TSI model 3077A) \\
\hline & Software: & TSI model $3772, \Delta T=17 \mathrm{~K}$ \\
\hline & CPC: & PSI scanning program \\
\hline & Sheath air flow: & $\begin{array}{l}\text { Closed-loop system with blower, mass flow meter and } \\
\text { heat exchanger }\end{array}$ \\
\hline & Aerosol flow: & Nafion dryer \\
\hline & Sensors: & $T, \mathrm{RH}$ in sheath air flow \\
\hline & HV power supply: & Negative \\
\hline \multirow[t]{15}{*}{ FMI-TDMPS } & Range: & $7-500 \mathrm{~nm}$ \\
\hline & DMA: & $\begin{array}{l}\text { Hauke-type (custom-made); inner diameter } 50 \mathrm{~mm} \text {, outer } \\
\text { diameter } 67 \mathrm{~mm} \text {, length } 280 \mathrm{~mm}\end{array}$ \\
\hline & UDMA (Ultrafine DMA): & $\begin{array}{l}\text { Hauke-type (custom-made); inner diameter } 50 \mathrm{~mm} \text {, outer } \\
\text { diameter } 67 \mathrm{~mm} \text {, length } 110 \mathrm{~mm}\end{array}$ \\
\hline & Bipolar diffusion charger: & ${ }^{85} \mathrm{Kr}(\mathrm{TSI}$ model 3077A) \\
\hline & CPC1: & TSI model $3772, \Delta T=25 \mathrm{~K}$ \\
\hline & CPC2: & TSI model $3772, \Delta T=25 \mathrm{~K}$ \\
\hline & Software: & UHEL stepping program \\
\hline & Sheath air flow DMA: & Closed-loop system and volumetric flow meters \\
\hline & Aerosol flow DMA: & $\Delta p$ capillary for volumetric flow and Nafion dryer \\
\hline & Sensors DMA: & $T, p$ in sheath air flow \\
\hline & HV power supply DMA: & Positive \\
\hline & Sheath air flow UDMA: & Closed-loop system and volumetric flow meters \\
\hline & Aerosol flow UDMA: & $T, p$ in sheath air flow \\
\hline & Sensors UDMA: & $\Delta p$ capillary for volumetric flow and Nafion dryer \\
\hline & HV power supply UDMA: & Positive \\
\hline \multirow[t]{9}{*}{$J R C-D M P S$} & Range: & $10-800 \mathrm{~nm}$ \\
\hline & DMA: & $\begin{array}{l}\text { Hauke-type (custom-made); inner diameter } 50 \mathrm{~mm} \text {, outer } \\
\text { diameter } 67 \mathrm{~mm} \text {, length } 280 \mathrm{~mm}\end{array}$ \\
\hline & Bipolar diffusion charger: & ${ }^{85} \mathrm{Kr}$ (TSI model 3077A) \\
\hline & CPC: & TSI model $3772, \Delta T=17 \mathrm{~K}$ \\
\hline & Software: & IFT stepping program \\
\hline & Sheath air flow: & $\begin{array}{l}\text { Closed-loop system with blower, heat exchanger, and } \\
\text { mass flow meter }\end{array}$ \\
\hline & Aerosol flow: & $\Delta p$ capillary for volumetric flow \\
\hline & Sensors: & $T, \mathrm{RH}$ in aerosol and sheath air flows \\
\hline & HV power supply: & Positive \\
\hline \multirow[t]{9}{*}{$L A M P-D M P S$} & Range: & $10-450 \mathrm{~nm}$ \\
\hline & DMA: & $\begin{array}{l}\text { TSI-type (custom-made); inner diameter } 18.8 \mathrm{~mm} \text {, outer } \\
\text { diameter } 39.2 \mathrm{~mm} \text {, length } 444 \mathrm{~mm}\end{array}$ \\
\hline & Bipolar diffusion charger: & ${ }^{63} \mathrm{Ni}($ non-commercial) \\
\hline & CPC: & TSI model $3010, \Delta T=17 \mathrm{~K}$ \\
\hline & Software: & LAMP stepping program \\
\hline & Sheath air flow: & $\begin{array}{l}\text { Closed-loop system with blower, mass flow meter, and } \\
\text { diffusion dryer }\end{array}$ \\
\hline & Aerosol flow: & $\begin{array}{l}\Delta p \text { capillary for volumetric flow and } \\
\text { diffusion dryer }\end{array}$ \\
\hline & Sensors: & $T, \mathrm{RH}$ in aerosol and sheath air flows \\
\hline & HV power supply: & Positive \\
\hline
\end{tabular}


Table A3. Continued.

\begin{tabular}{|c|c|c|}
\hline & & Description \\
\hline \multirow[t]{9}{*}{ NUIG-DMPS } & Range: & $20-500 \mathrm{~nm}$ \\
\hline & DMA: & $\begin{array}{l}\text { TSI model } 3081 \text { : inner diameter } 18.8 \mathrm{~mm} \text {, outer } \\
\text { diameter } 39.2 \mathrm{~mm} \text {, length } 444 \mathrm{~mm}\end{array}$ \\
\hline & Bipolar diffusion charger: & ${ }^{85} \mathrm{Kr}$ (TSI model 3077A) \\
\hline & CPC: & TSI model $3010, \Delta T=17 \mathrm{~K}$ \\
\hline & Software: & NUIG stepping program \\
\hline & Sheath air flow: & $\begin{array}{l}\text { Closed-loop system with critical orifice and vacuum pump, heat exchanger, and } \\
\text { mass flow meter }\end{array}$ \\
\hline & Aerosol flow: & $\Delta p$ capillary for volumetric flow and Nafion dryer \\
\hline & Sensors: & $T, \mathrm{RH}$ in aerosol and sheath air flow \\
\hline & HV power supply: & Positive \\
\hline \multirow[t]{9}{*}{ ISAC-DMPS } & Range: & $10-500 \mathrm{~nm}$ \\
\hline & DMA: & $\begin{array}{l}\text { Hauke-type (custom-made); inner radius } 50 \mathrm{~mm} \text {; outer } \\
\text { diameter; } 67 \mathrm{~mm} \text {, length } 280 \mathrm{~mm}\end{array}$ \\
\hline & Bipolar diffusion charger: & ${ }^{63} \mathrm{Ni}$ (non-commercial) \\
\hline & CPC: & TSI model $3010, \Delta T=17 \mathrm{~K}$ \\
\hline & Software: & University of Kuopio stepping program \\
\hline & Sheath air flow: & $\begin{array}{l}\text { Closed-loop system with critical orifice and vacuum pump, } \\
\text { heat exchanger, mass flow meter, and diffusion dryer }\end{array}$ \\
\hline & Aerosol flow: & $\Delta p$ capillaries for volumetric flow and Nafion dryer \\
\hline & Sensors: & $T, \mathrm{RH}$ in aerosol and sheath air flow \\
\hline & HV power supply: & Positive \\
\hline \multirow{9}{*}{$\begin{array}{l}\text { TNO-SMPS } \\
\text { TSI } 3034\end{array}$} & Range: & $10-500 \mathrm{~nm}$ \\
\hline & DMA: & $\begin{array}{l}\text { TSI for model 3034: inner diameter } 18.8 \mathrm{~mm} \text {, outer } \\
\text { diameter } 39.2 \mathrm{~mm} \text {, length } 333 \mathrm{~mm}\end{array}$ \\
\hline & Bipolar diffusion charger: & ${ }^{85} \mathrm{Kr}(\mathrm{TSI}$ model 3077A) \\
\hline & CPC: & TSI in-built (TSI model 3010 equivalent), $\Delta T=25 \mathrm{~K}$ \\
\hline & Software: & IFT scanning program \\
\hline & Sheath air flow: & Closed-loop system with blower \\
\hline & Aerosol flow: & $\Delta p$ over pre-impactor for volumetric flow and Nafion dryer \\
\hline & Sensors: & - \\
\hline & HV power supply: & Negative \\
\hline \multirow{9}{*}{$\begin{array}{l}\text { UBIR-SMPS } \\
\text { TSI } 3936\end{array}$} & Range: & $10-800 \mathrm{~nm}$ \\
\hline & DMA: & $\begin{array}{l}\text { TSI model } 3081 \text { : inner diameter } 18.8 \mathrm{~mm} \text {, outer } \\
\text { diameter } 39.2 \mathrm{~mm} \text {, length } 444 \mathrm{~mm}\end{array}$ \\
\hline & Bipolar diffusion charger: & ${ }^{85} \mathrm{Kr}(\mathrm{TSI}$ model $3077 \mathrm{~A})$ \\
\hline & CPC: & TSI model $3775, \Delta T=17 \mathrm{~K}$ \\
\hline & Software: & Software: TSI scanning program \\
\hline & Sheath air flow: & Closed-loop system with blower \\
\hline & Aerosol flow: & $\Delta p$ over pre-impactor for volumetric flow and Nafion dryer \\
\hline & Sensors: & - \\
\hline & HV power supply: & Negative \\
\hline
\end{tabular}

(e.g. aerosol flow and sheath air flow rate), and finally the number of size bins.

- The mandatory raw data include the measured system parameters and the measured electrical particle mobility distribution as described above. The data should be flagged according to the flag list as shown in Table A1, if measurement problems were identified.
- Optional data provide status parameters of the system. These data are meant for a future-orientated online data transfer showing the actual status of the instrument. These status parameters (e.g. standard deviation of the different flow rates, CPC temperatures and flow/liquid status) are necessary and important for an automated quality assurance procedure. 
Table A4a: Level-0 data structure for single mobility particle size spectrometers including mandatory and optional data and system parameters.

\begin{tabular}{|c|c|}
\hline \multicolumn{2}{|l|}{ mandatory } \\
\hline Column 01 & Start date (Day of Year - starting 1 Jan, 00:00 UTC with 0.00) \\
\hline Column 02 & End date (Day of Year - starting 1 Jan, 00:00 UTC with 0.00) \\
\hline Column 03 & Start year \\
\hline Column 04 & End year \\
\hline Column 05 & Internal system temperature $(\mathrm{K})$ \\
\hline Column 06 & Internal system pressure $(\mathrm{hPa})$ \\
\hline Column 07 & Flow rate - aerosol flow rate $\left(1 \mathrm{~min}^{-1}\right)$ at DMA temperature and pressure \\
\hline Column 08 & Flow rate - sheath air flow rate $\left(1 \mathrm{~min}^{-1}\right)$ at DMA temperature and pressure \\
\hline Column 09 & Relative humidity - aerosol flow (\%) \\
\hline Column 10 & Relative humidity - sheath air (\%) \\
\hline Column 11 & Number of particle size bins \\
\hline Column 12 & Size bin 01 median particle mobility diameter for singly charged particles (in $\mu \mathrm{m}$ ) \\
\hline Column ... & .../continue with all particle size bins \\
\hline Column ... & Size bin 01 (raw particle number concentrations in $\mathrm{cm}^{-3}$ ) \\
\hline Column ... & .../continue raw concentration for all particle size bins \\
\hline \multicolumn{2}{|l|}{ optional } \\
\hline Column ... & Size bin 01 Standard deviation - median particle mobility diameter (in $\mu \mathrm{m}$ ) \\
\hline Column ... & .../continue with all particle size bins \\
\hline Column ... & CPC saturator temperature $(\mathrm{K})$ \\
\hline Column ... & $\mathrm{CPC}$ condenser temperature $(\mathrm{K})$ \\
\hline Column ... & Standard deviation - aerosol flow rate $\left(1 \mathrm{~min}^{-1}\right)$ \\
\hline Column ... & Standard deviation - sheath air flow rate $\left(1 \mathrm{~min}^{-1}\right)$ \\
\hline Column ... & CPC flow rate status, $0-$ ok, $1-$ flow error \\
\hline Column ... & CPC liquid status, $0-$ ok, $1-$ liquid error \\
\hline Column ... & Sheath air flow rate status, $0-$ ok, 1 - flow not critical or unstable/low/high \\
\hline \multicolumn{2}{|l|}{ mandatory } \\
\hline Column ,,, & Numflag (data exist/do not exist/flagged $\longrightarrow 0 / 999 / \mathrm{nnn}$ ) \\
\hline
\end{tabular}

The whole level-0 data structures for single and dual DMA mobility particle size spectrometers are listed in Tables A4a and b, respectively. Data which do not fulfill the requirements must be flagged according to Table A1. False measurements should be removed from the data set and should be flagged as missing measurements.

In comment section of the metadata belonging to level0 , filtering of raw data should be described according to predefined Quality Control (QC). Accepted limits for system parameters such as flow rates, and RH:

- aerosol flow rate: maximum variation around set point $\pm 5 \%$ (recommendation)

- sheath air flow rate: maximum variation around set point $\pm 2 \%$ (recommendation).

\section{A4.2 Level-1}

Data in level-1 contain processed particle number size distributions with the original time resolution of the instrument (Table A5). The entire process includes:

- inversion from electrical particle mobility distribution to particle number size distribution (conversion to $\mathrm{d} N / \mathrm{d} \log D p$ and multiple charge correction)

- correction for CPC counting efficiency

- correction for internal losses due to particle diffusion

- correction for particle losses from the aerosol inlet to the instrument

- (optional) correction after comparison against reference mobility particle size spectrometer.

For dual DMA mobility particle size spectrometer only:

- assimilation of UDMA and DMA data 
Table A4b. Level-0 data structure for dual mobility particle size spectrometers including mandatory and optional data and system parameters.

\begin{tabular}{|c|c|}
\hline \multicolumn{2}{|l|}{ mandatory } \\
\hline Column 01 & Start date (Julian Day - starting 1 Jan, 00:00 UTC with 0.00) \\
\hline Column 02 & End date (Julian Day - starting 1 Jan, 00:00 UTC with 0.00) \\
\hline Column 03 & Start year \\
\hline Column 04 & End year \\
\hline Column 05 & DMA temperature $(\mathrm{K})$ \\
\hline Column 06 & DMA pressure $(\mathrm{hPa})$ \\
\hline Column 07 & Flow rate - aerosol flow rate $\left(1 \min ^{-1}\right)-$ UDMA \\
\hline Column 08 & Flow rate - sheath air flow rate $\left(1 \mathrm{~min}^{-1}\right)$ - UDMA \\
\hline Column 09 & Flow rate - aerosol flow rate $\left(1 \mathrm{~min}^{-1}\right)-\mathrm{DMA}$ \\
\hline Column 10 & Flow rate - sheath air flow rate $\left(1 \mathrm{~min}^{-1}\right)$ - DMA \\
\hline Column 11 & Relative humidity - aerosol flow (\%) - UDMA \\
\hline Column 12 & Relative humidity - sheath air (\%) - UDMA \\
\hline Column 13 & Relative humidity - aerosol flow (\%) - DMA \\
\hline Column 14 & Relative humidity - sheath air (\%) - DMA \\
\hline Column 15 & Number of size bins \\
\hline Column 16 & Size bin 01 median mobility particle diameter for singly charged particles (in $\mu \mathrm{m}$ ) \\
\hline Column ... & .../continue with all particle size bins \\
\hline Column ... & Size bin 01 (raw particle number concentrations in $\mathrm{cm}^{-3}$ ) \\
\hline Column ... & .../continue raw concentration for all particle size bins \\
\hline \multicolumn{2}{|l|}{ optional } \\
\hline Column ... & Size bin 01 Standard deviation - median particle diameter \\
\hline Column ... & .../continue for all particle size bins \\
\hline Column ... & Standard deviation - aerosol flow rate $\left(1 \mathrm{~min}^{-1}\right)$ - UDMA \\
\hline Column ... & Standard deviation - sheath air flow rate $\left(1 \mathrm{~min}^{-1}\right)$ - UDMA \\
\hline Column ... & Standard deviation - aerosol flow rate $\left(1 \mathrm{~min}^{-1}\right)-\mathrm{DMA}$ \\
\hline Column ... & Standard deviation - sheath air flow rate $\left(1 \mathrm{~min}^{-1}\right)-$ DMA \\
\hline Column ... & $\mathrm{CPC}$ saturator temperature $(\mathrm{K})$ \\
\hline Column ... & $\mathrm{CPC}$ condenser temperature $(\mathrm{K})$ \\
\hline Column ... & CPC1 flow status, $0-$ ok, $1-$ flow error \\
\hline Column ... & CPC2 flow status, $0-$ ok, 1 - flow error \\
\hline Column ... & CPC1 liquid status, 0 - ok, 1 - liquid error \\
\hline Column ... & CPC2 liquid status, 0 - ok, 1 - liquid error \\
\hline Column ... & Sheath air flow rate UDMA status, $0-$ ok, 1 - flow not critical or unstable/low/high \\
\hline Column ... & Sheath air flow rate DMA status, 0 - ok, 1 - flow not critical or unstable/low/high \\
\hline \multicolumn{2}{|l|}{ mandatory } \\
\hline Column ... & Numflag (data exist/do not exist/flagged $\longrightarrow 0 / 999 / \mathrm{nnn}$ ) \\
\hline
\end{tabular}

- removal of redundant size channels in the overlap region of UDMA and DMA.

In comment section of the metadata belonging to level-1 data, details should be listed about the transformations and corrections done from raw to processed data.

- For dual mobility particle size spectrometer only: which and how many bins form the overlap between UDMA and DMA were used.

- Description which inversion program with which bipolar charge equilibrium were used.
- Description of the correction functions for CPC efficiency, losses inside of the mobility particle size spectrometer, and losses in transport inlet system.

- (optional) Description of the correction function from comparison against a reference mobility particle size spectrometer.

- Calibration date of the CPC and DMA (in case a measured DMA transfer function is used in the inversion program). 
Table A5. Level-1 processed particle number size distribution with the original time resolution. Midpoint bin particle mobility diameter is given in the title of the column.

\begin{tabular}{ll}
\hline Column 01 & $\begin{array}{l}\text { Start date (Julian Day - starting 1 Jan, } \\
\text { 00:00 UTC with 0.00) }\end{array}$ \\
Column 02 & $\begin{array}{l}\text { End date (Julian Day - starting 1 Jan, } \\
\text { 00:00 UTC with 0.00) }\end{array}$ \\
Column 03 & Start year \\
Column 04 & End year \\
Column 05 & Internal system temperature (K) \\
Column 06 & Internal system pressure (hPa) \\
Column 07 & Number of particle size bins \\
Column 08 & Size bin 01 (dN/dlog Dp in cm $\left.{ }^{-3}\right)^{*}$ \\
& .../continue for all particle size bins \\
Column ... & Numflag (data exist/do not exist/flagged \\
& $\longrightarrow 0 / 999 / n n n)$ \\
\hline
\end{tabular}

* Zero values are replaced by a very small value such as $10^{-5}$.

\section{A4.3 Level-2}

Data in level-2 are the final particle number size distributions, which were corrected to standard conditions of temperature $(273.15 \mathrm{~K})$ and pressure $(1013.25 \mathrm{hPa})$, and averaged to a time resolution of $1 \mathrm{~h}$ (arithmetic mean). These final transformations are according to the standard in the EBAS data base. The data structure is described in Table A6 and consists of median values of the averaged particle number size distributions as well as their 15.87 and 84.13 percentiles.

As the WMO GAW-WDCA (World Data Centre for Aerosols) is hosted at the EMEP data center now, a minimum set of metadata parameters are required in the level-2 file header to meet the needs of WDCA. These requirements include station and instrument metadata for classifying the dataset in the database, e.g. instrument serial number, station GAW-ID, site land use and station settings. It also includes details about the corrections and calculations done.

Details about the corrections and calculations could alternatively be listed in comment section belonging to level-2 data.

- Correction to STP

- Calculations of average and percentile

- The DMA and the laminar flow element to determine the aerosol flow rate have to be cleaned once per year. CPCs have to undergo a service of an experienced person to clean the saturator and the optics.

- The bipolar diffusion charger should not be opened. The instructions of the manufacturer have to be followed.
Table A6. Level-2 processed particle number size distribution with the one hour time average at standard temperature and pressure. Bin particle mobility size is given in the title of the column.

\begin{tabular}{|c|c|}
\hline Column 01 & $\begin{array}{l}\text { Start date (Julian Day - starting } 1 \text { Jan, } \\
\text { 00:00 UTC with 0.00) }\end{array}$ \\
\hline Column 02 & $\begin{array}{l}\text { End date (Julian Day - starting } 1 \text { Jan, } \\
\text { 00:00 UTC with } 0.00 \text { ) }\end{array}$ \\
\hline Column 03 & Start year \\
\hline Column 04 & End year \\
\hline Column 05 & Internal system temperature $(\mathrm{K})$ \\
\hline Column 06 & Internal system pressure $(\mathrm{hPa})$ \\
\hline Column 07 & Number of particle size bins \\
\hline Column 08 & $\begin{array}{l}\text { Particle size bin } 01 \text { arithmetic mean } \\
\left(\mathrm{d} N / \mathrm{d} \log D p \text { in } \mathrm{cm}^{-3}\right)^{*}\end{array}$ \\
\hline Column ... & .../continue for all particle size bins \\
\hline Column ... & $\begin{array}{l}\text { Particle size bin } 01 \mathrm{~d} N / \mathrm{d} \log D p 15.87 \text { percentile } \\
\left(\mathrm{cm}^{-3}\right)\end{array}$ \\
\hline Column ... & .../continue for all particle size bins \\
\hline Column ... & $\begin{array}{l}\text { Particle size bin } 01 \mathrm{~d} N / \mathrm{d} \log D p 84.13 \text { percentile } \\
\left(\mathrm{cm}^{-3}\right)\end{array}$ \\
\hline Column ... & .../continue for all particle size bins \\
\hline Column ... & $\begin{array}{l}\text { Numflag (data exist/do not exist/flagged } \\
\longrightarrow 0 / 999 / \mathrm{nnn})\end{array}$ \\
\hline
\end{tabular}

* Zero values are replaced by a very small value such as $10^{-5}$.

Table A7. Approximation coefficients for the formula describing the bipolar charge distribution for the charging states $n(-2,-1,0$, $+1,+2$ ) (Wiedensohler, 1988; Baron and Willeke, 2005).

\begin{tabular}{rrrrrr}
\hline \multicolumn{5}{c}{ Approximation coefficients $a_{i}(n)$} \\
\cline { 2 - 6 }$i$ & $n=-2$ & $n=-1$ & $n=0$ & $n=+1$ & $n=+2$ \\
\hline 0 & -26.3328 & -2.3197 & -0.0003 & -2.3484 & -44.4756 \\
1 & 35.9044 & 0.6175 & -0.1014 & 0.6044 & 79.3772 \\
2 & -21.4608 & 0.6201 & 0.3073 & 0.4800 & -62.8900 \\
3 & 7.0867 & -0.1105 & -0.3372 & 0.0013 & 26.4492 \\
4 & -1.3088 & -0.1260 & 0.1023 & -0.1553 & -5.7480 \\
5 & 0.1051 & 0.0297 & -0.0105 & 0.0320 & 0.5049 \\
\hline
\end{tabular}

- The mobility particle size spectrometers should be operated in an environment of $15-30^{\circ} \mathrm{C}$ to avoid a malfunction of the particle counter.

\section{A5 Constants and relevant equations}

The constants and equations follow the recommendations in the ISO 15900 standardization (also given in Kim et al., 2005):

Dynamic gas viscosity at $296.15 \mathrm{~K}$ and $1013.25 \mathrm{hPa}$ :

$\eta_{0}=1.83245 \times 10^{-5} \mathrm{~kg} \mathrm{~m}^{-1} \mathrm{~s}^{-1}$ 
Table A8. Abbreviations of research institutes and universities.

\begin{tabular}{ll}
\hline Abbreviation & Research institutes and universities \\
\hline IFT & Leibniz Institute for Tropospheric Research, Leipzig, Germany \\
NILU & Norwegian Institute for Air Research, Kjeller, Norway \\
FMI & Finnish Meteorological Institute, Helsinki, Finland \\
LAMP & Laboratoire de Météorologie Physique, Clermont-Ferrand, France \\
UHEL & University of Helsinki, Helsinki, Finland \\
ULUND & Lund University, Lund Sweden \\
PSI & Paul Scherrer Institute, Villigen, Switzerland \\
JRC & Joint Research Centre, Ispra, Italy \\
UBIR & University of Birmingham, Birmingham, United Kingdom \\
NUIG & National University of Ireland, Galway, Ireland \\
ISAC & Institute of Atmospheric Sciences and Climate, Bologna, Italy \\
TNO & TNO Built Environment and Geosciences, Utrecht, The Netherlands \\
UMN & University of Minnesota, Minneapolis, USA \\
PKU & Peking University, Beijing, China \\
\hline
\end{tabular}

$\eta=\eta_{0}\left(\frac{T}{T_{0}}\right)^{3 / 2}\left(\frac{T_{0}+110.4 \mathrm{~K}}{T+110.4 \mathrm{~K}}\right)$.

Mean free path at $296.15 \mathrm{~K}$ and $1013.25 \mathrm{hPa}$ :

$\lambda_{0}=67.3 \times 10^{-9} \mathrm{~m}$

$\lambda=\lambda_{0}\left(\frac{T}{T_{0}}\right)^{2}\left(\frac{p_{0}}{p}\right)\left(\frac{T_{0}+110.4 \mathrm{~K}}{T+110.4 \mathrm{~K}}\right)$.

Cunningham correction:

$C_{\mathrm{C}}=1+\frac{2 \cdot \lambda}{\mathrm{d}_{\mathrm{P}}}\left(1.165+0.483 \cdot \exp \left(-0.997 \frac{\mathrm{d}_{\mathrm{P}}}{2 \cdot \lambda}\right)\right)$.

Bipolar charge distribution:

To calculate the bipolar charge distribution analytically, an approximation formula for lower charging states, $n,(-2,-1$, $+1,+2$ ) was developed (Wiedensohler, 1988). This formula is valid for particle size ranges from 1 to $1000 \mathrm{~nm}$ or 20 to $1000 \mathrm{~nm}$ particle diameter for $n$ equal to $-1,0,+1$ or -2 , +2 , respectively. The according approximation coefficients are given in Table A7.

Approximation formula:

$F(n)=10^{\left(\sum_{i=0}^{5} a_{i}(n)\left(\log \frac{D_{\mathrm{P}}}{\mathrm{nm}}\right)^{i}\right)}$.

For higher $n(+3,-3,+4,-4$ etc. $)$, the Gunn formula below can be used. A ratio of the electrical mobility of positive to negative ions $Z_{\mathrm{I}+} / Z_{\mathrm{I}-}$ of $1.4 / 1.6$ was suggested in Wiedensohler (1988).

Gunn (1956) equation:

$$
\begin{aligned}
F(n)= & \frac{e}{\sqrt{4 \pi^{2} \cdot \varepsilon_{0} \cdot D_{\mathrm{P}} \cdot k \cdot T}} \\
& \cdot \exp \left(-\frac{\left(n-\left(\frac{2 \pi \cdot \varepsilon_{0} \cdot D_{\mathrm{P}} \cdot k \cdot T}{e^{2}}\right) \ln \frac{Z_{\mathrm{I}+}}{Z_{\mathrm{I}-}}\right)^{2}}{\left(\frac{4 \pi \cdot \varepsilon_{0} \cdot D_{\mathrm{P}} \cdot k \cdot T}{e^{2}}\right)}\right) .
\end{aligned}
$$

\section{A5.1 EUSAAR format: TSI-mobility particle size spectrometer}

TSI-AIM raw data are particle counts versus time. The raw data are exported by AIM as shown below. The export also contains all parameters needed for all further calculations. The raw data time listed in this table is elapsed time since the start of the scan, the particle counts have been detected by the CPC at this elapsed time. As can be seen, the CPC is read 10 times per second.

The raw data export table also lists the particle diameter for singly charged particles $\left(D^{1+}\left(t_{\mathrm{e}, i}\right)\right)$ which corresponds to the elapsed time $\left(t_{\mathrm{e}, i}\right)$. This diameter can be used to show raw counts versus particle size. The raw particle counts can either be accumulated in the time interval from $t_{\mathrm{e}, i-1}$ to $t_{\mathrm{e}, i}$ or in the diameter interval from $D^{1+}\left(t_{\mathrm{e}, i-1}\right)$ to $D^{1+}\left(t_{\mathrm{e}, i}\right)$. Knowing the effective aerosol flow rate of the condensation particle counter, the number can be converted to a particle number concentration. The mid particle diameter is determined by the geometric mean of the lower $D^{1+}\left(t_{\mathrm{e}, i-1}\right)$ and upper diameter $D^{1+}\left(t_{\mathrm{e}, i}\right)$ of the chosen channel width.

\section{A5.2 EUSAAR format: Grimm-mobility particle size spectrometer}

The Grimm mobility particle size spectrometers record the measured raw electrical mobility distribution according to the EUSAAR Level-0 data format indicated as particle number concentration for each particle diameter bin.

\section{A6 Abbreviation list of universities and research institutes}

The abbreviations of the research institutes and universities, which participated in the intercomparison of inversion routines and instruments, are listed in Table A8. 
Acknowledgements. This work was accomplished by the European research infrastructure projects EUSAAR (European Supersites for Atmospheric Aerosol Research, EU FP6 Integrated Infrastructures Initiatives project, No. FP6-026140), and ACTRIS (Aerosols, Clouds, and Trace gases Research InfraStructure Network). The research leading to these results has received funding from the European Union Seventh Framework Programme (FP7/20072013) project No. 262254). Additionally, we acknowledge the network of excellence ACCENT (Atmospheric Composition Change: a European Network, EU FP6 Network of Excellence project, No. GOCE-CT-2004-505337) and the WCCAP (World Calibration Centre for Aerosol Physics as part of the WMO-GAW program; Global Atmosphere Watch) funded by the Federal Environmental Agency of Germany (Umweltbundesamt), EUCAARI (European Integrated project on Aerosol Cloud Climate and Air Quality Interactions), the Marie Curie Initial Training Network CLOUD-ITN (EC FP7 grant No. 215072), the German Federal Ministry for the Environment, Nature Protection and Reactor Safety (Bundesministerium für Umwelt, Naturschutz und Reaktorsicherheit) grant F\&E 3707 43200, and the project "Qualitätskontrolle der Messung ultrafeiner Partikel in der Außenluft im Jahr 2011" funded by the Saxon State Office for Environment, Agriculture and Geology (Sächsisches Landesamt für Umwelt, Landwirtschaft und Geologie). Atmospheric data generated within EUSAAR/ACTRIS/WMO-GAW are stored at EBAS, a database developed and operated by the Norwegian Institute for Air Research (NILU). EBAS hosts observation data of atmospheric aerosol chemical composition and physical properties. Figure 1 was kindly prepared by A. Haudek (IfT).

Edited by: J.-L. Jimenez

\section{References}

Agarwal, J. K. and Sem, G. J.: Continuous flow, single-particlecounting condensation nucleaus counter, J. Aerosol Sci., 11, 343-357, 1980.

Asmi, A., Wiedensohler, A., Laj, P., Fjaeraa, A.-M., Sellegri, K., Birmili, W., Weingartner, E., Baltensperger, U., Zdimal, V., Zikova, N., Putaud, J.-P., Marinoni, A., Tunved, P., Hansson, H.C., Fiebig, M., Kivekäs, N., Lihavainen, H., Asmi, E., Ulevicius, V., Aalto, P. P., Swietlicki, E., Kristensson, A., Mihalopoulos, N., Kalivitis, N., Kalapov, I., Kiss, G., de Leeuw, G., Henzing, B., Harrison, R. M., Beddows, D., O’Dowd, C., Jennings, S. G., Flentje, H., Weinhold, K., Meinhardt, F., Ries, L., and Kulmala, M.: Number size distributions and seasonality of submicron particles in Europe 2008-2009, Atmos. Chem. Phys., 11, 5505-5538, doi:10.5194/acp-11-5505-2011, 2011.

Baron, P. A. and Willeke, K.: Aerosol Measurement: Principles, Techniques, and Applications, 2nd Edn., Wiley-Interscience, 2005.

Birmili, W., Stratmann, F., Wiedensohler, A., Covert, D., Russell, L. M., and Berg, O.: Determination of differential mobility analyzer transfer functions using identical instruments in series, Aerosol Sci. Tech., 27, 215-223, 1997.

Birmili, W., Stratmann, F., and Wiedensohler, A.: Design of a DMA-based size spectrometer for a large particle size range and stable operation, J. Aerosol Sci., 30, 549-553, 1999.
Birmili, W., Wiedensohler, A., Heintzenberg, J., and Lehmann, K.: Atmospheric particle number size distribution in central Europe: statistical relations to air masses and meteorology, J. Geophys. Res., 106, 32005-32018, 2001.

Birmili, W., Schepanski, K., Ansmann, A., Spindler, G., Tegen, I., Wehner, B., Nowak, A., Reimer, E., Mattis, I., Müller, K., Brüggemann, E., Gnauk, T., Herrmann, H., Wiedensohler, A., Althausen, D., Schladitz, A., Tuch, T., and Löschau, G.: A case of extreme particulate matter concentrations over Central Europe caused by dust emitted over the southern Ukraine, Atmos. Chem. Phys., 8, 997-1016, doi:10.5194/acp-8-997-2008, 2008.

Birmili, W., Weinhold, K., Nordmann, S., Wiedensohler, A., Spindler, G., Müller, K., Herrmann, H., Gnauk, T., Pitz, M., Cyrys, J., Flentje, H., Nickel, C., Kuhlbusch, T. A. J., Löschau, G., Haase, D., Meinhardt, F., Schwerin, A., Ries, L., and Wirtz, K.: Atmospheric aerosol measurements in the German Ultrafine Aerosol Network (GUAN): Part 1: Soot and particle number size distributions, Gefahrst. Reinh. Luft, 69, 137-145, 2009.

Charron, A. and Harrison, R. M.: Primary particle formation from vehicle emissions during exhaust dilution in the roadside atmosphere, Atmos. Environ., 37, 4109-4119, 2003.

Chen, D. R., Pui, D. Y. H., Hummes, D., Fissan, H., Quant, F. R., and Sem, G. J.: Design and evaluation of a nanometer aerosol differential mobility analyzer (Nano-DMA), J. Aerosol Sci., 29, 497-509, 1998.

Collins, D. R., Flagan, R. C., and Seinfeld, J. H.: Improved inversion of scanning DMA data, Aerosol Sci. Tech., 36, 1-9, 2002.

Covert, D. S., Wiedensohler, A., and Russell, L. M.: Charging and transmission efficiencies of aerosol charge neutralizers, Aerosol Sci. Tech., 27, 206-214, 1997.

Dahmann, D., Riediger, G., Schlatter, J., Wiedensohler, A., Carli, S., Graff, A., Grosser, M., Hojgr, M., Horn, H.-G., Jing, L., Matter, U., Monz, C., Mosimann, T., Stein, H., Wehner, B., and Wieser, U.: Intercomparison of mobility particle sizers (MPS), Gefahrst. Reinh. Luft, 61, 423-428, 2001.

Dick, W., Huang, P. F., and McMurry, P. H.: Characterization of 0.02 to $1.0 \mu \mathrm{m}$ particle losses in Perma Pure dryers: dependency on size, charge and relative humidity, PTL Publication No. 936: Particle Technologogy Laboratory, Department of Mechanical Engineering, University of Minnesota, Minneapolis, MN 55455, 1995.

Fiebig, M., Stein, C., Schröder, F., Feldpausch, P., and Petzold, A.: Inversion of data containing information on the aerosol particle size distribution using multiple instruments, J. Aerosol Sci., 36, 1353-1372, 2005.

Fissan, H., Helsper, C., and Thielen, H.: Determination of particle size distributions by means of an electrostatic classifier, J. Aerosol Sci., 14, 354-357, 1983.

Fissan, H., Hummes, D., Stratmann, F., Büscher, P., Neumann, S., Pui, D. Y. H., and Chen, D.: Experimental comparison of four differential mobility analyzers for nanometer aerosol measurements, Aerosol Sci. Tech., 24, 1-13, 1996.

Flagan, R. C.: On Differential mobility analyzer resolution, Aerosol Sci. Tech. 30, 556-570, 1999.

Fletcher, R. A., Mulholland, G. W., Winchester, M. R., King, R. L., and Klinedinst, D. B.: Calibration of a condensation particle counter using a NIST traceable method, Aerosol Sci. Tech., 43, 425-441, 2009. 
Fuchs, N. A.: On the stationary charge distribution on aerosol particles in a bipolar ionic atmosphere, Geofis. Pura. Appl., 56, 185193, 1963.

Gunn, R.: The hyperelectrification of raindrops by atmospheric electric fields, J. Meteorol., 13, 283-288, 1956.

Hagen, D. E. and Alofs, D. J.: Linear inversion method to obtain aerosol size distributions from measurements with a differential mobility analyzer, Aerosol Sci. Tech., 2, 465-475, 1983.

Hagwood, C., Sivathanu, Y., and Mulholland, G.: The DMA transfer function with Brownian motion, a trajectory/Monte-Carlo approach, Aerosol Sci. Tech., 30, 40-61, 1999.

Helsper, C., Horn, H. G., Schneider, F., Wehner, B., and Wiedensohler, A.: Intercomparison of five mobility size spectrometers for measuring atmospheric submicrometer aerosol particles, Gefahrst. Reinh. Luft, 68, 475-481, 2008.

Hermann, M., Wehner, B., Bischof, O., Han, H.-S., Krinke, T., Liu, W., Zerrath, A., and Wiedensohler, A.: Particle counting efficiencies of new TSI condensation particle counters, J. Aerosol Sci., 38, 674-682, 2007.

Hinds, W. C.: Aerosol Technology: Properties, Behaviour and Measurement of Airborne Particles, 2nd Edn., John Wiley, New York, 1999.

Hoppel, W.: Determination of the aerosol size distribution from the mobility distribution of the charged fraction of aerosols, J. Aerosol Sci., 9, 41-54, 1978.

Hoppel, W. A. and Frick, G. M.: Ion-aerosol attachment coefficients and the steady-state charge distribution on aerosols in a bipolar ion environment, Aerosol Sci. Tech., 5, 1-21, 1986.

Imhof, D., Weingartner, E., Prévôt, A. S. H., Ordóñez, C., Kurtenbach, R., Wiesen, P., Rodler, J., Sturm, P., McCrae, I., Ekström, M., and Baltensperger, U.: Aerosol and $\mathrm{NO}_{\mathrm{x}}$ emission factors and submicron particle number size distributions in two road tunnels with different traffic regimes, Atmos. Chem. Phys., 6, 22152230, doi:10.5194/acp-6-2215-2006, 2006.

Jiang, J., Attoui, M., Heim, M., Brunell, N. A., McMurry, P. H., Kasper, G., Flagan, R. C., Giapis, K., and Mouret, G.: Transfer functions and penetrations of five differential mobility analyzers for sub-2 nm particle classification, Aerosol Sci. Tech., 45, 480492, 2011.

Jokinen, V. and Mäkelä, J. M.: Closed-loop arrangement with critical orifice for DMA sheath excess flow system, J. Aerosol. Sci., 28, 643-648, 1997.

Karlsson, M. N. A. and Martinsson, B. G.: Methods to measure and predict the transfer function size dependence of individual DMAs, J. Aerosol Sci., 34, 603-625, 2003.

Kim, J. H., Mulholland, G. W., Kukuck, S. R., and Pui, D. Y. H.: Slip correction measurements of certified PSL nanoparticles using a nanometer Differential Mobility Particle Analyzer (NanoDMA) for Knudsen number from 0.5 to 83, J. Res. Natl. Inst. Stand. Tech., 110, 31-54, 2005.

Khlystov, A., Kos, G. P. A., ten Brink, H. M., Mirme, A., Tuch, T., Roth, C., and Kreyling, W. G.: Comparability of three spectrometers for monitoring urban aerosol, Atmos. Environ., 35, 20452051, 2001.

Knutson, E. O.: Extended Electric Mobility Method for Measuring Aerosol Particle Size and Concentration, in: Fine Particles: Aerosol Generation, Measurement, Sampling, and Analysis, edited by: Liu, B. Y. H., Academic Press, New York, 739$762,1976$.
Knutson, E. O. and Whitby, K. T.: Aerosol classification by electric mobility: apparatus, theory and applications, J. Aerosol Sci., 6, 443-451, 1975.

Kousaka, Y., Okuyama, K., and Adachi, M.: Determination of particle size distribution of ultrafine aerosols using a differential mobility analyzer, Aerosol Sci. Tech., 4, 209-225, 1985.

Liu, B. Y. H. and Pui, D. Y. H.: Submicron aerosol standard and primary, absolute calibration of the condensation nuclei counter, J. Colloid Interf. Sci., 47, 155-171, 1974.

Mäkelä, J. M., Koponen, I. K., Aalto, P., and Kulmala, M.: Oneyear data of submiron size modes of tropospheric background aerosol in southern Finland, J. Aerosol Sci., 31, 595-611, 2000.

Mulholland, G. W., Donnelly, M. K., Hagwood, C. R., Kukuck, S. R., Hackley, V. A., and Pui, D. Y. H.: Measurement of $100 \mathrm{~nm}$ and $60 \mathrm{~nm}$ particle standards by differential mobility analysis, J. Res. Natl. Inst. Stand. Tech., 111, 257-312, 2006.

Reineking, A. and Porstendörfer, J.: Measurements of particle loss functions in a differential mobility analyzer (TSI, Model 3071) for Different Flow Rates, Aerosol Sci. Tech., 5, 483-486, 1986.

Russell, L. M., Flagan, R. C., and Seinfeld, J. H.: Asymmetric instrument response resulting from mixing effects in accelerated DMA-CPC measurements, Aerosol Sci. Tech., 23, 491-509, 1995.

Scheibel, H. G. and Porstendörfer, J.: Generation of monodisperse $\mathrm{Ag}$ - and $\mathrm{NaCl}$-aerosols with particle diameters between 2 and 300 nm, J. Aerosol Sci., 14, 113-126, 1983.

Schladitz, A., Müller, T., Massling, A., Kaaden, N., Kandler, K., and Wiedensohler, A.: In situ measurements of optical properties at Tinfou (Morocco) during the Saharan Mineral Dust Experiment SAMUM 2006, Tellus B, 61, 64-78, 2009.

Stratmann, F. and Wiedensohler, A.: A new data inversion algorithm for DMPS-measurements, J. Aerosol Sci., 27 (Suppl. 1), 339-340, 1996.

Stolzenburg, M.: An Ultrafine Aerosol Size Distribution Measuring System, PhD. thesis, Mechanical Engineering Department, University of Minnesota, USA, 1988.

Stolzenburg, M. R. and McMurry, P. H.: An ultrafine aerosol condensation nucleus counter, Aerosol Sci. Tech., 14, 48-65, 1991.

Stolzenburg, M. R. and McMurry, P. H.: Equations governing single and tandem DMA configurations and a new lognormal approximation to the transfer function, Aerosol Sci. Tech., 42, 421-432, 2008.

Swietlicki, E., Hansson, H.-C., Hämeri, K., Svenningsson, B., Massling, A., McFiggans, G., McMurry, P. H., Petäjä, T., Tunved, P., Gysel, M., Topping, D., Weingartner, E., Baltensperger, U., Rissler, J., Wiedensohler, A., and Kulmala, M.: Hygroscopic properties of sub-micrometer atmospheric aerosol particles, 60, 432-469, 2008.

ten Brink, H., Plomp, A., Spoelstra, H., and van de Vate, J.: A high resolution electrical mobility aerosol spectrometer (MAS), J. Aerosol Sci., 14, 589-597, 1983.

Tuch, T., Brand, P., Wichmann, H. E., and Heyder, J.: Variation of particle number and mass concentration in various size ranges of ambient aerosols in Eastern Germany, Atmos. Environ., 31, 4193-4197, 1997.

Tuch, T. M., Haudek, A., Müller, T., Nowak, A., Wex, H., and Wiedensohler, A.: Design and performance of an automatic regenerating adsorption aerosol dryer for continuous operation at monitoring sites, Atmos. Meas. Tech., 2, 417-422, 
doi:10.5194/amt-2-417-2009, 2009.

Tunved, P., Hansson, H.-C., Kulmala, M., Aalto, P., Viisanen, Y., Karlsson, H., Kristensson, A., Swietlicki, E., Dal Maso, M., Ström, J., and Komppula, M.: One year boundary layer aerosol size distribution data from five nordic background stations, Atmos. Chem. Phys., 3, 2183-2205, doi:10.5194/acp-3-2183-2003, 2003.

Wang, J., Flagan, R., and Seinfeld, J.: Diffusional losses in particle sampling systems containing bends and elbows, Aerosol Sci. Tech., 33, 843-857, 2002.

Wang, S. and Flagan, R.: Scanning electrical mobility spectrometer, J. Aerosol Sci., 13, 230-240, 1990.

Wang, X. L, Kaufman, S. L., Sem, G. J., Stolzenburg, M. R., and McMurry, P. H.: Experimental and Numerical Studies of Particle Transmission Efficiency through Aerosol Neutralizers, AAAR annual meeting Reno, 2007.

Wehner, B. and Wiedensohler, A.: Long term measurements of submicrometer urban aerosols: statistical analysis for correlations with meteorological conditions and trace gases, Atmos. Chem. Phys., 3, 867-879, doi:10.5194/acp-3-867-2003, 2003.

Weingartner, E., Nyeki, S., and Baltensperger, U.: Seasonal and diurnal variation of aerosol size distributions $(10<D<750 \mathrm{~nm})$ at a high-alpine site (Jungfraujoch $3580 \mathrm{~m}$ a.s.1.), J. Geophys. Res., 104, 26809-26820, 1999.

Wiedensohler, A.: An approximation of the bipolar charge distribution for particles in the submicron size range, J. Aerosol Sci., 19, 387-389, 1988.
Wiedensohler, A., Orsini, D., Covert, D. S., Coffmann, D., Cantrell, W., Havlicek, M., Brechtel, F. J., Russell, L. M., Weber, R. J., Gras, J., Hudson, J. G., and Litchy, M.: Intercomparison study of the size-dependent counting efficiency of 26 condensation particle counters, Aerosol Sci. Tech., 27, 224-242, 1997.

Winklmayr, W., Reischl, G., Lindner, A., and Berner, A.: A new electromobility spectrometer for the measurement of aerosol size distributions in the size range from 1 to $1000 \mathrm{~nm}$, J. Aerosol Sci., 22, 289-296, 1991.

WMO: GAW Aerosol Measurement procedures guidelines and recommendations. WMO Report 153, Geneva, Switzerland, 2003.

Woo, K. S., Chen, D. R., Pui, D. Y. H., and McMurry, P. H.: Measurement of Atlanta aerosol size distributions: Observations of ultrafine particle events, Aerosol Sci. Tech., 34, 75-87, 2001.

Yli-Ojanperä, J., Mäkelä, J. M., Marjamäki, M., Rostedt, A., and Keskinen, J.: Towards traceable particle number concentration standard: Single charged aerosol reference (SCAR), J. Aerosol Sci., 41, 719-728, 2010.

Zhang, S. H. and Flagan, R. C.: Resolution of the radial differential mobility analyzer for ultrafinene particles, J. Aerosol Sci., 27, 1179-1200, 1996.

Zhou, J.: Hygroscopic Properties of Atmospheric Aerosol Particles in Various Environments, Doctoral dissertation, ISBN 91-7874120-3, Lund University, Dept. of Nuclear Physics, Lund, Sweden, 2001. 